\title{
Atlantic Ocean Heat Transport Influences Interannual-to-Decadal Surface Temperature Predictability in the North Atlantic Region
}

\author{
LEONARD F. BORCHERT \\ Institute for Oceanography, CEN, Universität Hamburg, and International Max Planck Research School on \\ Earth System Modelling, Max Planck Institute for Meteorology, Hamburg, Germany \\ Wolfgang A. MÜLleR \\ Deutscher Wetterdienst, and Max Planck Institute for Meteorology, Hamburg, Germany \\ JOHANNA BAEHR \\ Institute for Oceanography, CEN, Universität Hamburg, Hamburg, Germany
}

(Manuscript received 27 October 2017, in final form 19 May 2018)

\begin{abstract}
An analysis of a three-member ensemble of initialized coupled simulations with the MPI-ESM-LR covering the period 1901-2010 shows that Atlantic northward ocean heat transport (OHT) at $50^{\circ} \mathrm{N}$ influences surface temperature variability in the North Atlantic region for several years. Three to ten years after strong OHT phases at $50^{\circ} \mathrm{N}$, a characteristic pattern of sea surface temperature (SST) anomalies emerges: warm anomalies are found in the North Atlantic and cold anomalies emerge in the Gulf Stream region. This pattern originates from persistent upper-ocean heat content anomalies that originate from southward-propagating OHT anomalies in the North Atlantic. Interannual-to-decadal SST predictability of yearly initialized hindcasts is linked to this SST pattern: when ocean heat transport at $50^{\circ} \mathrm{N}$ is strong at the initialization of a hindcast, SST anomaly correlation coefficients in the northeast Atlantic at lead years 2-9 are significantly higher than when the ocean heat transport at $50^{\circ} \mathrm{N}$ is weak at initialization. Surface heat fluxes that mask the predictable lowfrequency oceanic variability that influences SSTs in the northwest Atlantic after strong OHT phases, and in the northwest and northeast Atlantic after weak OHT phases at $50^{\circ} \mathrm{N}$ lead to zonally asymmetrically predictable SSTs 7-9 years ahead. This study shows that the interannual-to-decadal predictability of North Atlantic SSTs depends strongly on the strength of subpolar ocean heat transport at the start of a prediction, indicating that physical mechanisms need to be taken into account for actual temperature predictions.
\end{abstract}

\section{Introduction}

Climate prediction several years ahead has received increasing scientific attention in recent years (e.g., Palmer et al. 2004; Smith et al. 2007; Keenlyside et al. 2008; Doblas-Reyes et al. 2013; Müller et al. 2014). Prediction skill was found in the North Atlantic region and in surface temperatures over Europe on time scales of 2-8 years (e.g., Smith et al. 2007; Yeager et al. 2012; Müller et al. 2012). While prediction skill for surface temperatures was found to be generally weak over continental regions, it was found to be high over the ocean. This stems from the inertia of the ocean, a

Corresponding author: Leonard F. Borchert, leonard.borchert@ mpimet.mpg.de memory in the climate system, which preconditions interannual-to-decadal temperature predictability in the North Atlantic region (e.g., Branstator and Teng 2010; Matei et al. 2012; Collow et al. 2015). Recent studies suggested that phases of strong meridional transport of heat (OHT) in the Atlantic Ocean linked to the Atlantic meridional overturning circulation (AMOC) influence North Atlantic upper ocean heat content [UOHC; defined as the heat contained in the top $700 \mathrm{~m}$ of the ocean, e.g., in Zhang and Zhang (2015)], which might improve surface temperature predictability on a time scale of 212 years (Zhang 2008; Zhang and Zhang 2015). However, the specific influence of the strength of the OHT on the predictability of North Atlantic UOHC and surface temperatures was not yet investigated. By using the fully coupled Max Planck Institute Earth System Model 
(MPI-ESM) initialized between 1901 and 2010, we analyze the dependency of the interannual-to-decadal predictability of North Atlantic UOHC, sea surface temperatures (SSTs), and surface air temperatures (SATs) on the state of the OHT at $50^{\circ} \mathrm{N}$ at the start of the prediction.

Interannual-to-decadal SST and SAT predictions in the North Atlantic were demonstrated to be skillful in some recent studies (e.g., Matei et al. 2012; Yeager et al. 2012; Klöwer et al. 2014; Müller et al. 2014; Robson et al. 2018). These studies generally agree that predictive skill on these time scales originates from the persistence of UOHC in the North Atlantic (e.g., Müller et al. 2014), thus concluding that, if UOHC is predictable, surface temperature is potentially predictable as well (e.g., Matei et al. 2012; Robson et al. 2012; Yeager et al. 2012).

Low-frequency variability of the oceanic circulation was shown to precondition predictive skill of UOHC and SSTs on the interannual-to-decadal time scale in case studies. Specifically, the 1960s cooling of the North Atlantic Subpolar Gyre (Robson et al. 2014), and the 1920s (Müller et al. 2014) and 1990s (Yeager et al. 2012; Robson et al. 2013) warmings were shown to be predictable several years in advance when the state of the ocean was initialized in the respective model simulation. These studies showed that individual events of persistent UOHC anomalies in the North Atlantic could have been predicted in the past, leading to possible predictability for SATs over parts of Europe as well (Robson et al. 2012). Predictive skill for UOHC was also found to be dependent on the start date of the prediction, which was hypothesized to originate from variability in Atlantic oceanic circulation (e.g., Yeager et al. 2012; Brune et al. 2017). To understand interannual-todecadal predictability of SSTs and SATs in the North Atlantic, it is therefore paramount to understand UOHC dynamics and predictability.

Changes in UOHC in the North Atlantic are controlled by convergence of heat in the ocean and vertical heat fluxes [surface heat fluxes (SHFs)] at the ocean-atmosphere interface. Oceanic heat convergence changes UOHC slowly, whereas SHFs are responsible for more short-term variability in UOHC. Predictable persistent patterns of UOHC can therefore be found in areas where ocean heat convergence contributes more strongly to anomalous UOHC than SHFs (e.g., Häkkinen et al. 2015). Zhang (2008) and Zhang and Zhang (2015) described a mechanism connecting strong phases of AMOC-related ocean heat transport to ocean heat convergence and consequently UOHC variability in the North Atlantic. Strong phases of the AMOC and associated OHT in the northern North Atlantic were shown to originate from surface density anomalies in the subpolar North Atlantic and to propagate southward at a slow advection speed. The authors showed that this slow southward propagation of strong OHT phases led to a heat convergence anomaly north of the OHT anomaly and a heat divergence anomaly south of the OHT anomaly, constituting a UOHC anomaly dipole between positive anomalies in the North Atlantic Subpolar Gyre and negative anomalies in the Gulf Stream region, the so-called AMOC fingerprint (Zhang and Zhang 2015). Because of the slow propagation speed, the time lag between the initial AMOC and OHT anomaly at $50^{\circ} \mathrm{N}$ and the AMOC fingerprint was found to be between 2 and 12 years, depending on the model setup (Zhang and Zhang 2015). The AMOC fingerprint was also seen to influence surface temperatures and therefore was hypothesized to influence the skill of interannual-to-decadal UOHC and SST predictions (Zhang 2008; Zhang and Zhang 2015).

Here, we analyze predictability after strong and weak OHT phases at $50^{\circ} \mathrm{N}$ separately to assess the specific influence of strong and weak OHT phases on North Atlantic surface temperature predictions. Because initialized model experiments rely on observations or reanalyses for initialization, they typically cover the time from 1960 to today. This time frame is not sufficient to examine strong and weak OHT phases separately and obtain statistically robust results for each phase individually. Müller et al. (2015) used fluxes of freshwater, heat, and momentum at the ocean surface derived from the Twentieth Century Reanalysis (Compo et al. 2011) to force the Max Planck Institute Ocean Model (MPIOM; Jungclaus et al. 2013) at the surface and derive a four-dimensional ocean state estimate for 1872-2010. They showed that this model simulation realistically reproduces the observed multidecadal variability in the ocean over the entire time series. In Müller et al. (2014), the authors assimilated this ocean state estimate into the fully coupled MPI-ESM for the period 1901-2010, and started 10-yr-long hindcasts with the free fully coupled model every January. These simulations were shown to skillfully predict North Atlantic surface temperature for up to 10 years (Müller et al. 2014). We use this set of initialized hindcasts to examine the predictive skill of UOHC and SSTs after strong and weak OHT anomalies separately at different time lags between 1901 and 2010.

\section{Model and methods}

We use three assimilation experiments of fully coupled simulations with the general circulation model MPI-ESM in its low-resolution (LR) setup for the period 1901-2010 from Müller et al. (2014). The model 
version uses the ocean model MPIOM (Jungclaus et al. 2013) at an average horizontal resolution of $1.5^{\circ}$ and 40 vertical levels and the atmospheric model ECHAM6 (Stevens et al. 2013) at the horizontal resolution T63 with 47 vertical levels with the top at $0.1 \mathrm{hPa}$. The coupled model was nudged daily toward three-dimensional ocean temperatures and salinity fields (Müller et al. 2014), taken from an ensemble of MPIOM simulations forced every $6 \mathrm{~h}$ by fluxes of heat, freshwater, and momentum through bulk formulas at the ocean surface (Müller et al. 2015). These fluxes were taken for the period 1872-2010 from the Twentieth Century Reanalysis (Compo et al. 2011). We remove the mean seasonal cycle from each ensemble member of the assimilation experiment separately and then form an ensemble mean of the three realizations of the assimilation run. We then detrend the ensemble mean and form anomalies against its mean state. The resulting detrended ensemble mean of anomalies will be referred to as "ASSIM" in this paper.

At the beginning of every year between 1901 and 2010, a 10-yr-long hindcast simulation with the free fully coupled MPI-ESM-LR was started (Müller et al. 2014). We remove the mean seasonal cycle from every ensemble member individually. The individual ensemble members of the hindcast experiments are bias corrected against the corresponding realization of the MPIOM simulation from Müller et al. (2015). We then form an ensemble mean of the realizations of the hindcasts. The resulting ensemble means are detrended, and anomalies against the respective mean state are formed. The resulting detrended and bias-corrected ensemble mean hindcasts will be abbreviated as "HC."

Starting coupled model simulations from assimilation experiments can lead to a strong drift, where model physics and real physics disagree (e.g., Smith et al. 2013; Sanchez-Gomez et al. 2016; Pohlmann et al. 2017). Because the ocean state estimate used here for assimilation was based on the same model version as the ocean component of the coupled model into which it was assimilated, and, because it was forced exclusively at the ocean surface, data assimilation in this simulation represents a relatively soft approach to data assimilation. This potentially reduces the amount of drift that can be expected from this assimilation model simulation. Moreover, the interior ocean can freely adjust to the surface forcing. This enables an examination of the temporal and spatial development of surface-induced changes in the ocean state and dynamics, like the mechanism leading to the AMOC fingerprint (Zhang and Zhang 2015), with limited perturbance from data assimilation. On the other hand, a surface-forced ocean state estimate might represent the three-dimensional ocean state only to a limited degree; however, the ocean state estimate that was used to produce ASSIM was previously found to produce reasonable climate variability in the North Atlantic region that is in agreement with observations and reanalyses in the atmosphere as well as the ocean for the entire twentieth century, such as the 1960s cooling and the 1920s and 1990s warmings (Müller et al. 2015).

A drawback of the $\mathrm{HC}$ simulations is the limited ensemble size of three members. Nonetheless, the HC ensemble mean was shown to reproduce climate variability in the North Atlantic region robustly for the entire time series 1901-2010, which led to an increase in North Atlantic surface temperature prediction skill when using 1901-2010 for the evaluation of skill compared to 1960-2010 (Müller et al. 2014). Because of the aforementioned reasons, ASSIM and HC are appropriate tools for the examination of the research questions brought forward in this paper.

To examine the mechanism leading to the AMOC fingerprint, we need to examine the propagation of anomalies of the AMOC maximum across latitudes (Zhang and Zhang 2015). The AMOC was in the past shown to show particular meridional coherence when it is calculated in density coordinates (Zhang 2010). We therefore use AMOC anomalies in density coordinates, calculated from vertical diapycnal transports that are calculated from divergences of horizontal transports. We define total OHT in time $[Q(t)]$ as the depthand longitude-integrated product of three-dimensional $y$-velocity $v$ and potential temperature $\Theta$ fields as in Jayne and Marotzke (2001). This is formulated as

$$
Q(t)=\rho_{0} c_{p} \iint_{-H}^{0} v \Theta d z d x
$$

where $\rho_{0}$ is the density of seawater $\left(1025 \mathrm{~kg} \mathrm{~m}^{-3}\right)$, and $c_{p}$ is the specific heat of seawater $\left(3994 \mathrm{~J} \mathrm{~kg}^{-1}{ }^{\circ} \mathrm{C}^{-1}\right)$ integrated over depth $z$ up to maximum depth $H$, and longitudinal extent of the Atlantic basin $x$ (Jayne and Marotzke 2001). Upper ocean heat content [UOHC $(t)$ ] at every horizontal grid point is calculated by integrating potential temperature $\Theta$ in the upper $700 \mathrm{~m}$ of the ocean, which are the upper 20 layers in our model:

$$
\operatorname{UOHC}(t)=\rho_{0} c_{p} \int_{700 \mathrm{~m}}^{0 \mathrm{~m}} \Theta d z
$$

For SHF we use in our study the total surface heat fluxes over sea. This includes shortwave, longwave, sensible, and latent heat fluxes. These fluxes are defined positive downward.

We form annual means of OHT, AMOC, UOHC, SSTs, and SHFs, and annual and seasonal means of SHFs and SATs for winter (JFM), spring (AMJ), summer (JAS), and 

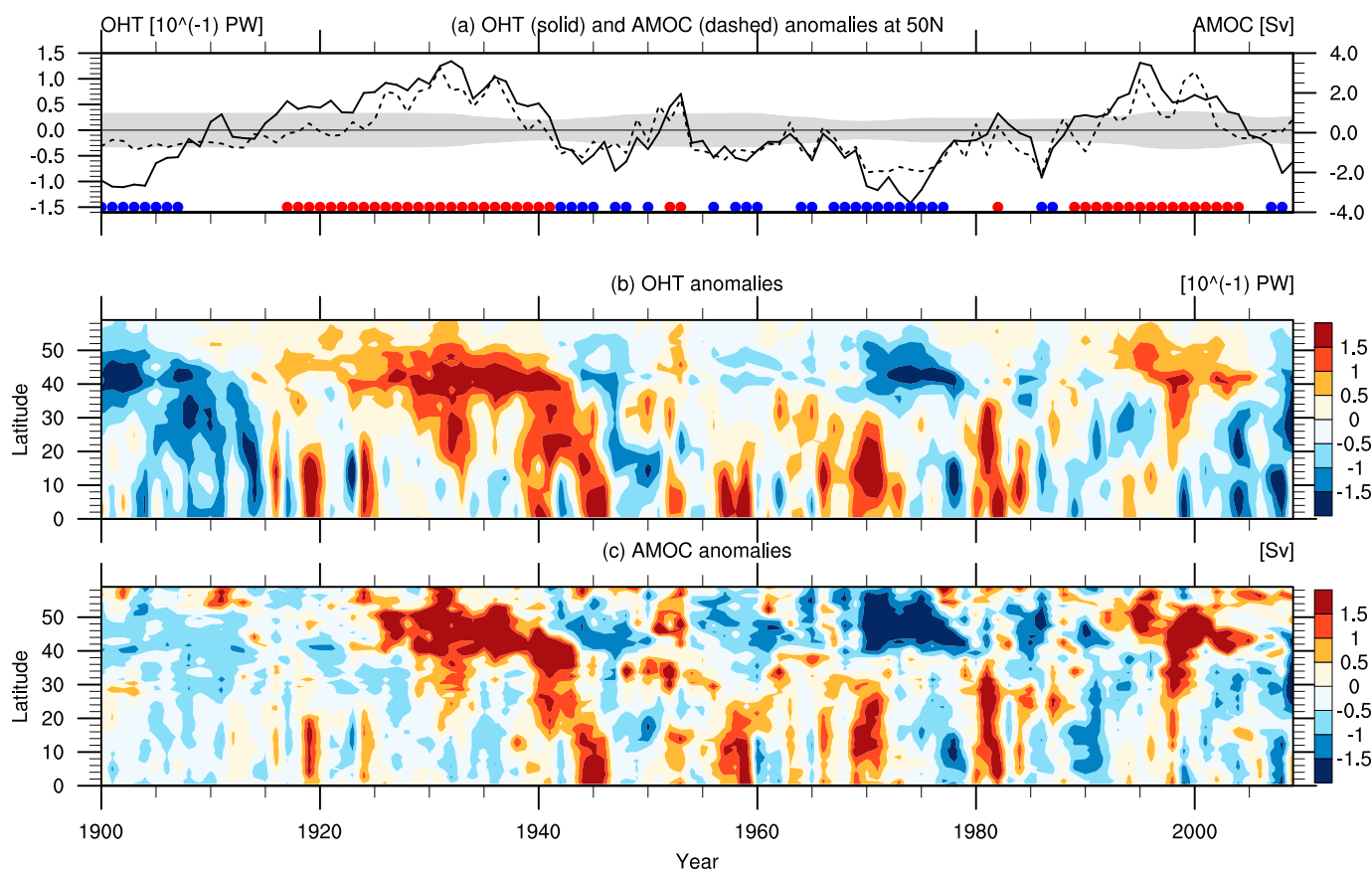

FIG. 1. (a) Detrended anomalies of AMOC maximum at $50^{\circ} \mathrm{N}$ (dashed line, Sv) and total $\mathrm{OHT}$ at $50^{\circ} \mathrm{N}$ (solid line, $10^{-1} \mathrm{PW}$ ) in the ASSIM simulation. The gray area denotes a half standard deviation above and below the mean of the previous 30 years. Strong and weak OHT phases (i.e., years where the solid line lies outside the gray area), are marked with red and blue dots at the bottom, respectively. Hovmöller diagrams of (b) OHT anomalies and (c) AMOC maximum anomalies illustrate the development of strong and weak anomalies of OHT and AMOC in space ( $y$ axis, ${ }^{\circ}$ latitude) and time ( $x$ axis, years). OHT and AMOC time series are detrended at each latitude.

autumn (OND) from HC and ASSIM. We test whether composite mean climate states related to strong and weak $\mathrm{OHT}$ phases at $50^{\circ} \mathrm{N}$ are statistically different from the mean climate variability using a two-sided $t$ test. We assess predictive skill of HC against ASSIM using anomaly correlation coefficients (ACCs). ACCs are formulated as

$$
\mathrm{ACC}=\frac{\sum_{i=1}^{n} f_{i}^{\prime} a_{i}^{\prime}}{\sqrt{\sum_{i=1}^{n} f_{i}^{\prime 2} \sum_{i=1}^{n} a_{i}^{2}}},
$$

where $n$ is the number of samples, $f^{\prime}$ is the anomaly of the forecast value, and $a^{\prime}$ is the anomaly of the verifying value (Jolliffe and Stephenson 2012). The statistical significance of the skill estimates of the predictions presented in this paper is assessed using a Monte Carlo procedure. The predictability we discuss here is tested using a leave-oneout cross validation (Arlot and Celisse 2010).

\section{A physical OHT and surface temperature mechanism}

We analyze the meridional coherence of AMOC maximum and total OHT in our assimilation model experiment ASSIM, and test whether AMOC variability is linked to heat transport variability in our model. This link between AMOC and OHT is an important feature of the dynamical mechanism driving the AMOC fingerprint (Zhang and Zhang 2015). Annual mean anomalies of AMOC maximum and OHT are largely coherent at $50^{\circ} \mathrm{N}$ (corr $=0.84$, Fig. $\left.1 \mathrm{a}\right)$, and seem closely connected across the whole North Atlantic at both multidecadal and interannual-to-decadal time scales (Figs. 1b,c). In ASSIM, the twentieth century is characterized by substantial multidecadal variability in both AMOC and OHT with strong anomalies in the 1920s and 1990s and with an episode of weak anomalies in between. This variability is similar to previously published estimates (e.g., Robson et al. 2013, 2014; Müller et al. 2014).

\section{a. The influence of OHT on SSTs}

OHT anomalies directly affect changes in UOHC. As the aim of this study is to diagnose the reason for UOHC changes contributing to the AMOC fingerprint (Zhang 2008) here, we focus on OHT instead of AMOC dynamics. It is worth noting, however, that none of the findings presented in this paper change significantly if the AMOC maximum was used instead of total OHT. 


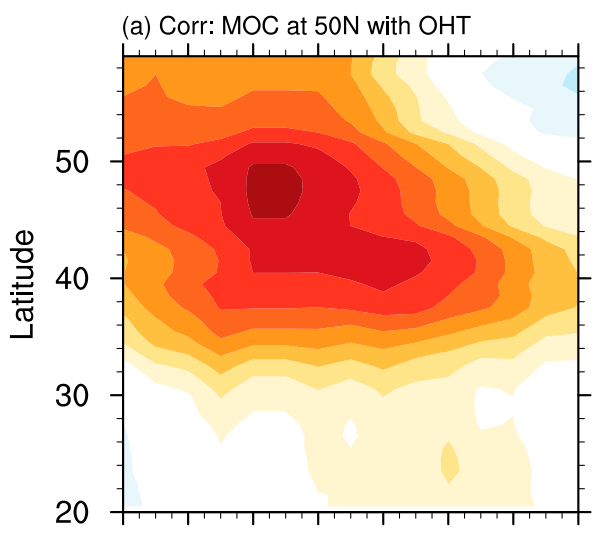

(c) Corr: OHT with ocean heat convergence

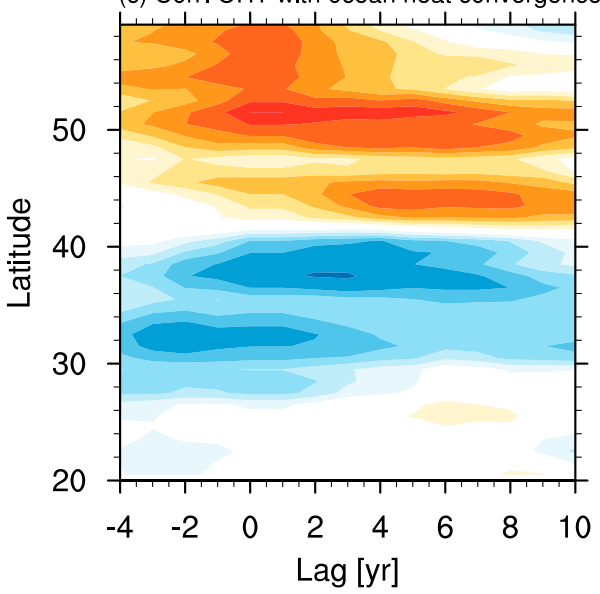

(b) Corr: $\mathrm{OHT}$ at $50 \mathrm{~N}$ with $\mathrm{OHT}$

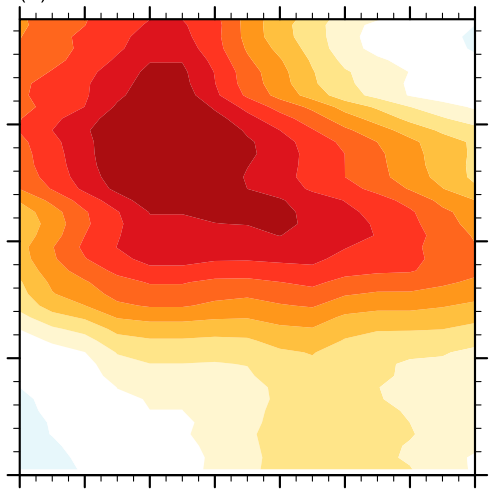

\begin{tabular}{|l|l}
\hline & 0.8 \\
0.7 & 0.6 \\
\hline & 0.5 \\
0.4 & 0.3 \\
\hline & 0.2 \\
\hline & 0.1 \\
\hline
\end{tabular} 0.8 0.7 0.6 0.5 0.4 0.3 0.2 0

(d) Corr: OHT with ocean heat convergence -0.1

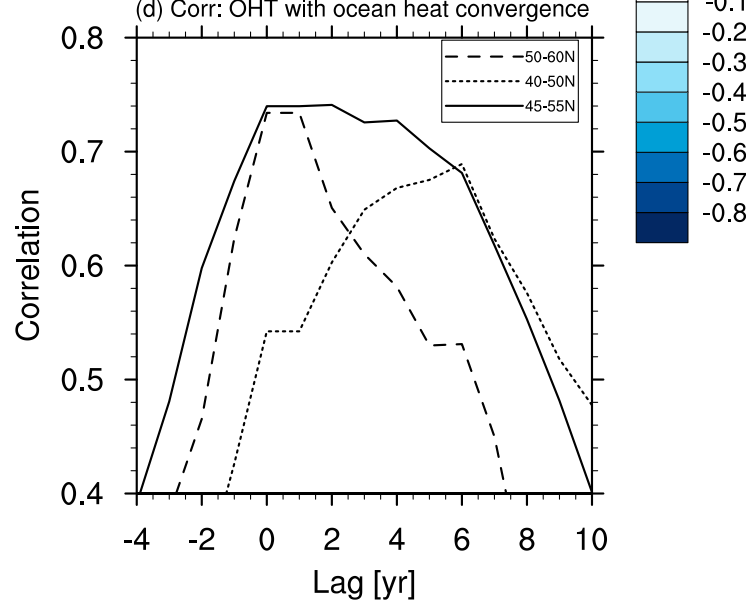

FIG. 2. ASSIM-based lead-lag correlations of OHT at $50^{\circ} \mathrm{N}$ with (a) AMOC maximum anomalies, (b) OHT anomalies, and (c) ocean heat convergence. (d) Lead-lag correlations of $\mathrm{OHT}$ at $45^{\circ}, 50^{\circ}$, and $55^{\circ} \mathrm{N}$ with oceanic heat convergence between $40^{\circ}-50^{\circ} \mathrm{N}, 45^{\circ}-55^{\circ} \mathrm{N}$, and $50^{\circ}-60^{\circ} \mathrm{N}$, respectively. Positive lags indicate OHT at $50^{\circ} \mathrm{N}$ leads, and vice versa.

OHT anomalies generally originate in the North Atlantic between $50^{\circ}$ and $60^{\circ} \mathrm{N}$ and propagate southward slowly; this propagation is closely linked to AMOC dynamics (Figs. 2a,b). South of $35^{\circ} \mathrm{N}$, both AMOC and OHT anomalies show only limited correlation to OHT anomalies at $50^{\circ} \mathrm{N}$, and the correlation that can be seen shows the same lag to OHT at $50^{\circ} \mathrm{N}$ between $20^{\circ}$ and $35^{\circ} \mathrm{N}$. The latter indicates that south of $35^{\circ} \mathrm{N}$, AMOC and $\mathrm{OHT}$ anomalies propagate southward at the speed of a coastal Kelvin wave as described in Zhang and Zhang (2015).

OHT anomalies at $50^{\circ} \mathrm{N}$ and ocean heat convergence anomalies between $55^{\circ}$ and $40^{\circ} \mathrm{N}$ several years later are highly correlated (Fig. 2c). This effect is in line with the findings of Zhang and Zhang (2015) and results from the slow southward propagation of the OHT anomaly north of $35^{\circ} \mathrm{N}$. Because the $\mathrm{OHT}$ anomaly propagates more slowly southward than it advects heat northward, an ocean heat convergence anomaly arises just north of the
OHT anomaly, and an ocean divergence anomaly arises just south of the OHT anomaly. The heat convergence signal is particularly strong and long-lasting between $45^{\circ}$ and $55^{\circ} \mathrm{N}$, where we find a high positive correlation when OHT at $50^{\circ} \mathrm{N}$ leads ocean heat convergence by $0-8$ years (Figs. 2c,d). The time lags of maximum correlation between OHT anomalies at $50^{\circ} \mathrm{N}$ and ocean heat convergence anomalies decrease with increasing latitude of the ocean heat convergence area (Fig. 2d). Because of the faster propagation of the OHT anomalies south of $35^{\circ} \mathrm{N}$, we do not find an ocean heat convergence signal south of $40^{\circ} \mathrm{N}$ (Fig. 2c). The strong and long-lasting ocean heat convergence anomalies north of $40^{\circ} \mathrm{N}$ accumulate heat and potentially lead to persistent UOHC (Dong et al. 2007; Zhang and Zhang 2015).

In ASSIM, we find an area of UOHC in the North Atlantic to be significantly correlated with $\mathrm{OHT}$ variability at $50^{\circ} \mathrm{N}$ at lag 0 , and when $\mathrm{OHT}$ at $50^{\circ} \mathrm{N}$ leads by $3-5$ and $7-9$ years (Figs. 3a-c). The area where $\mathrm{UOHC}$ is 

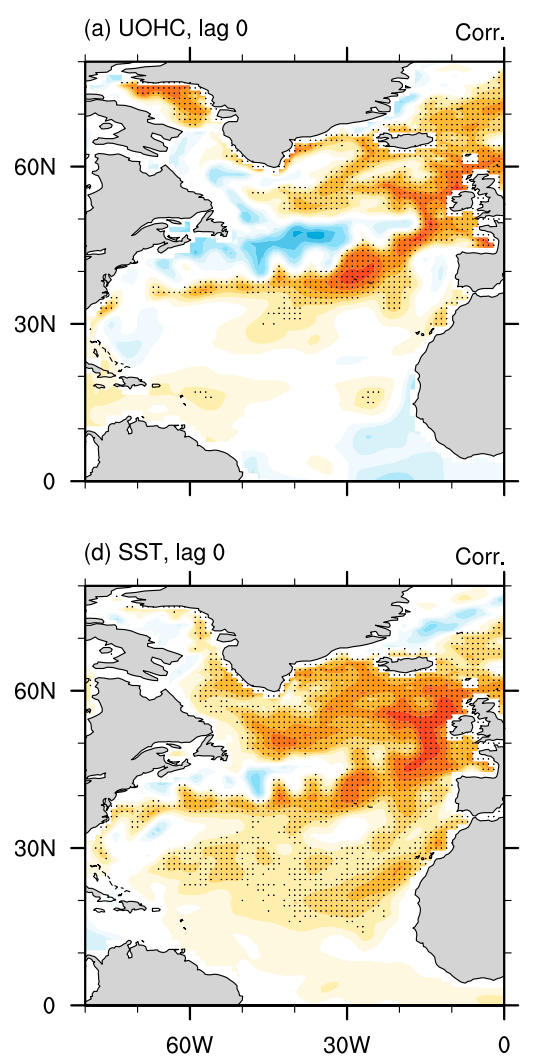
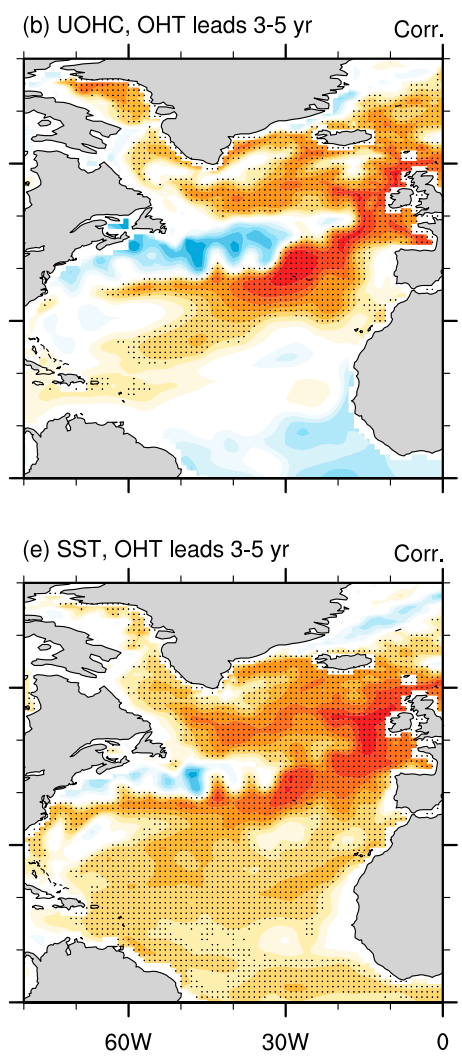
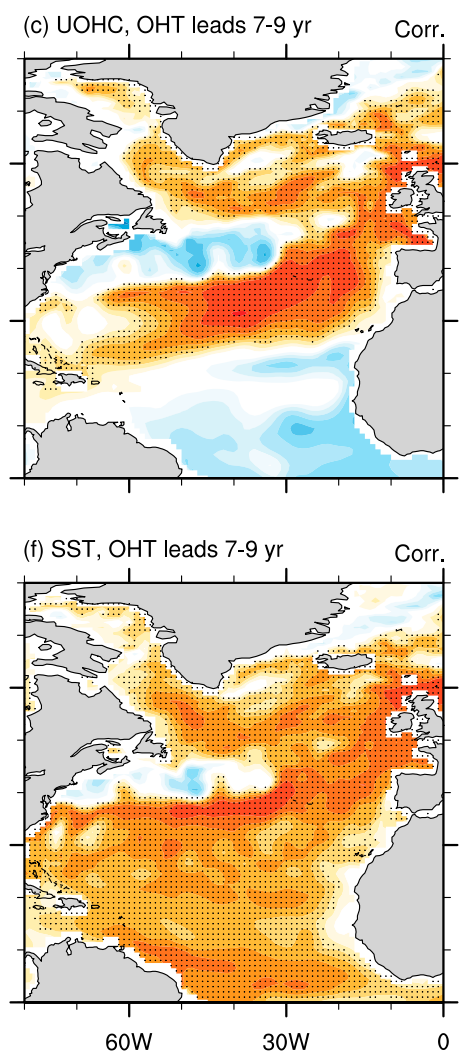

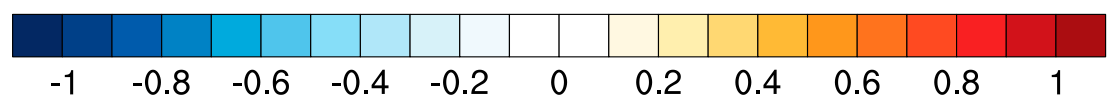

FIG. 3. Point-by-point correlation of $\mathrm{OHT}$ at $50^{\circ} \mathrm{N}$ with upper-ocean heat content of the upper $700 \mathrm{~m}$ in the North Atlantic in ASSIM at (a) lag 0 and when OHT leads by (b) 3-5 years and (c) 7-9 years, and with SSTs at (d) lag 0 and when OHT leads by (e) 3-5 years and (f) 7-9 years. Stippling indicates significant correlations at the $99 \%$ level.

most strongly influenced by $\mathrm{OHT}$ at $50^{\circ} \mathrm{N}$ is located in the northeast North Atlantic and forms a crescent shape around a strong negative correlation in the Gulf Stream region. Overall correlation coefficients increase with increasing lead time, although the pattern persists. SST anomalies (Figs. 3d-f) show largely the same shape of correlation to $\mathrm{OHT}$ anomalies at $50^{\circ} \mathrm{N}$ as $\mathrm{UOHC}$ at all time lags (cf. Figs. 3a-c). As with UOHC, the influence of OHT at $50^{\circ} \mathrm{N}$ increases with increasing time that $\mathrm{OHT}$ at $50^{\circ} \mathrm{N}$ leads. Much of the increase in influence is found north of $40^{\circ} \mathrm{N}$. Correlation patterns of sea surface height anomalies to OHT at $50^{\circ} \mathrm{N}$ are very similar to those of UOHC, while correlation patterns of sea surface salinity to $\mathrm{OHT}$ phases at $50^{\circ} \mathrm{N}$ are very similar to those of SSTs (not shown). This is in line with recent findings (e.g., Zhang and Zhang 2015). In conjunction with the similar time lags we find in this analysis and in the ocean heat convergence signal identified above (cf. Figs. 2c,d), we conclude that the mechanism Zhang and Zhang (2015) described leading to the AMOC fingerprint is responsible for the OHT-UOHC/SST correlation pattern, and that the model setup we use is appropriate to study the effect of this mechanism on UOHC and SST predictability.

The UOHC and SST pattern we find looks different from the pattern Zhang and Zhang (2015) described. Specifically, we find the strongest positive anomaly in the northeast Atlantic, while Zhang and Zhang (2015) find it in the central subpolar gyre. Because of the different UOHC and SST pattern in the MPI-ESM-LR, we will hereafter refrain from calling this pattern the AMOC fingerprint to avoid confusion, but will instead refer to the MPI-ESM-LR-specific AMOC fingerprint as the characteristic SST pattern.

\section{b. Strong and weak $O H T$ phases at $50^{\circ} \mathrm{N}$}

Going beyond Zhang and Zhang (2015), we examine the emergence of the characteristic SST pattern and the role of UOHC in more detail with particular attention to strong and weak phases of the $\mathrm{OHT}$ at $50^{\circ} \mathrm{N}$. We analyze 
composite mean OHT anomalies in the North Atlantic before, during, and after strong and weak OHT anomalies at $50^{\circ} \mathrm{N}$ in ASSIM separately. For that, we subsample ocean states for years where the $\mathrm{OHT}$ at $50^{\circ} \mathrm{N}$ is at least half a standard deviation above or below its mean of the preceding 30 years. No conclusions presented in this study change strongly if other possible criteria are used to select strong and weak OHT phases at $50^{\circ} \mathrm{N}$ (e.g., a full standard deviation above or below the mean, or above or below the mean of the previous 30 years).

Composite mean OHT anomalies in the North Atlantic before, during, and after strong and weak OHT anomalies at $50^{\circ} \mathrm{N}$, similar to the correlations presented in Fig. 2a, are shown in Figs. 4a and 4b. OHT anomalies associated with strong $\mathrm{OHT}$ phases at $50^{\circ} \mathrm{N}$ show a very pronounced and long-lived positive OHT anomaly between $50^{\circ}$ and $35^{\circ} \mathrm{N}$ that persists up to 9 years after the strong OHT anomaly at $50^{\circ} \mathrm{N}$ (Fig. 4a). For weak OHT phases at $50^{\circ} \mathrm{N}$, the negative $\mathrm{OHT}$ anomaly disappears almost completely 6 years after the OHT anomaly at $50^{\circ} \mathrm{N}$ (Fig. $4 \mathrm{~b}$ ). This leads to different ocean heat convergence signals between phases of strong and weak OHT at $50^{\circ} \mathrm{N}$.

We show composite mean cumulative heat convergence anomalies to illustrate the influence of strong and weak $\mathrm{OHT}$ at $50^{\circ} \mathrm{N}$ on the heat that accumulates in the ocean: cumulative heat convergence is calculated by integrating ocean heat convergence anomalies at every latitude in time between the OHT anomaly at $50^{\circ} \mathrm{N}$ and time lags between -4 and 10 (Figs. $4 \mathrm{c}, \mathrm{d}$ ). Strong OHT phases at $50^{\circ} \mathrm{N}$ are followed by a strong and long-lived cumulative heat convergence anomaly that extends approximately from $45^{\circ}$ to $55^{\circ} \mathrm{N}$ after 5 years (Fig. 4c). This cumulative heat convergence anomaly is strongest between $45^{\circ}$ and $55^{\circ} \mathrm{N}$ compared to other latitudinal bands (Fig. 4e). Weak OHT phases at $50^{\circ} \mathrm{N}$ are followed by a weak cumulative heat divergence anomaly that emerges at longer lag of 6 or more years and extends from $50^{\circ} \mathrm{N}$ northward (Fig. 4d). Here, a positive cumulative heat convergence anomaly south of $50^{\circ} \mathrm{N}$ and a negative cumulative heat convergence anomaly north of $50^{\circ} \mathrm{N}$ are stronger than the heat convergence anomaly between $45^{\circ}$ and $55^{\circ} \mathrm{N}$ (Fig. 4f). This indicates that the effect of OHT anomalies at $50^{\circ} \mathrm{N}$ on the characteristic SST pattern is strong between $45^{\circ}$ and $55^{\circ} \mathrm{N}$ after strong OHT phases at $50^{\circ} \mathrm{N}$ and weak after weak OHT phases at $50^{\circ} \mathrm{N}$.

Composite mean upper-ocean heat content anomalies during and after phases of strong and weak OHT at $50^{\circ} \mathrm{N}$ (Fig. 5) show a similar shape as the UOHC correlation maps in Figs. 3a-c (keeping in mind that positive correlations correspond to positive composite means for strong OHT phases and vice versa). Following strong OHT phases at $50^{\circ} \mathrm{N}$, a strong positive UOHC anomaly between $45^{\circ}$ and $55^{\circ} \mathrm{N}$ appears in the northeast Atlantic and increases in strength over time (Figs. 5a-c). In contrast, the UOHC anomaly is only weakly negative in this area after weak $\mathrm{OHT}$ phases at $50^{\circ} \mathrm{N}$ at all time lags (Figs. 5d-f). This is in line with the different signals we find in the composite mean cumulative heat convergence anomalies (cf. Figs. 4c-f).

We find a dipole between the Gulf Stream region and its southeastern edge in composite mean UOHC anomalies (Fig. 5). This pattern can be attributed to composite mean cumulative ocean heat convergence anomalies as well (cf. Figs. 4c-f). However, it appears to be a symmetric response as this pattern arises after both weak and strong OHT phases at similar strengths.

Composite mean SST anomalies compared to the composite mean UOHC anomalies described above show a similar pattern north of $40^{\circ} \mathrm{N}$ (Fig. 6). We find a strong signal in composite mean SSTs in the northeast Atlantic that propagates westward over time after both strong and weak OHT phases at $50^{\circ} \mathrm{N}$. There is almost no signal in SST composite means south of $40^{\circ} \mathrm{N}$. After strong OHT phases at $50^{\circ} \mathrm{N}$, composite mean SST anomalies grow contiuously stronger over time (Figs. 6a-c), whereas composite mean SST anomalies after weak OHT phases at $50^{\circ} \mathrm{N}$ become very weak in the northeast Atlantic after 7-9 years (Fig. 6f). We therefore conclude that ocean heat convergence influences SSTs most strongly in the northeast Atlantic several years after phases of strong $\mathrm{OHT}$ at $50^{\circ} \mathrm{N}$.

Significant composite mean SHFs (contours in Fig. 6; upward SHFs generally correspond to positive SST anomalies and vice versa) show some asymmetries between strong and weak OHT phases at $50^{\circ} \mathrm{N}$. Note that we use total values and no anomalies for SHFs. Specifically, a zonal asymmetry appears after 7-9 years with upward SHFs across most of the North Atlantic between $50^{\circ}$ and $55^{\circ} \mathrm{N}$ and $20^{\circ}$ and $50^{\circ} \mathrm{W}$ where SST composites are high after strong OHT phases at $50^{\circ} \mathrm{N}$ (Fig. 6c). We find downward SHFs in the Labrador Sea and in the northeast Atlantic between $50^{\circ}$ and $55^{\circ} \mathrm{N}$ and $10^{\circ}$ and $20^{\circ} \mathrm{W}$ where SST anomalies are weak after weak OHT phases at $50^{\circ} \mathrm{N}$ (Fig. 6f). These areas can be regarded as areas where SHFs contribute strongly to SST variability alongside OHT. This finding indicates that the ocean influences the atmosphere more strongly after strong OHT phases at $50^{\circ} \mathrm{N}$ than after weak OHT phases at $50^{\circ} \mathrm{N}$.

\section{c. SATs influenced by OHT and SHFs}

SHFs show stronger seasonal variability than the interior ocean, as SHFs are influenced by atmospheric 

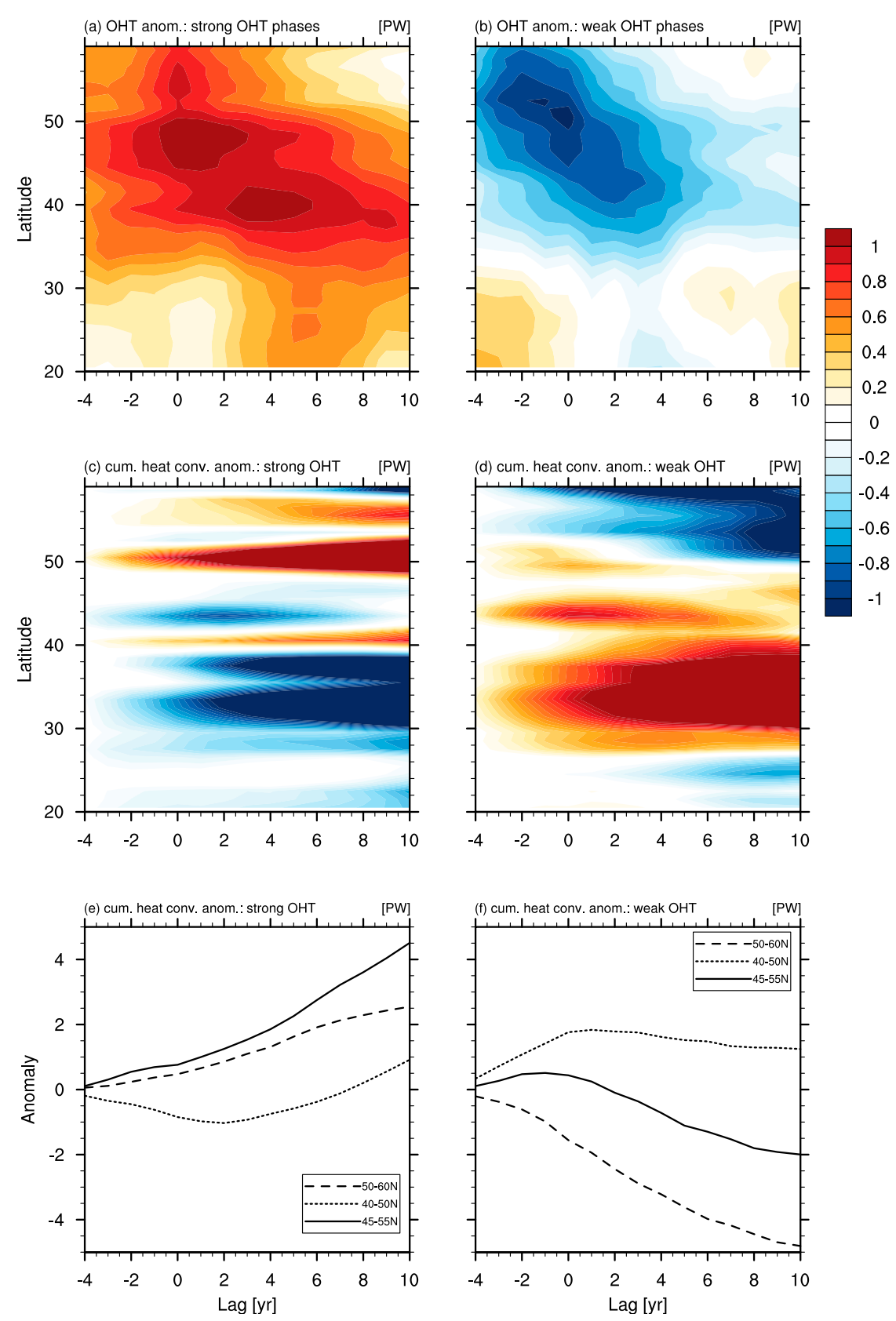

FIG. 4. Composite means before, during, and after (left) strong and (right) weak OHT phases at $50^{\circ} \mathrm{N}$ in ASSIM. (a),(b) Mean OHT anomalies and (c),(d) cumulative ocean heat convergence relative to lag 0 against latitude. Composite mean cumulative heat convergence between $40^{\circ}$ and $50^{\circ} \mathrm{N}, 45^{\circ}$ and $55^{\circ} \mathrm{N}$, and $50^{\circ}$ and $60^{\circ} \mathrm{N}$ for (e) strong and (f) weak OHT phases at $45^{\circ}, 50^{\circ}$, and $55^{\circ} \mathrm{N}$, respectively. Positive lags indicate $\mathrm{OHT}$ at $50^{\circ} \mathrm{N}$ leads, and vice versa.

variability. We therefore examine the influence of SHFs on SATs at seasonal means. This allows us to assess the oceanic influence on SATs at the seasonal level as shown by Arthun et al. (2017). Because of the strong SHFs we found in the previous section (cf. Fig. 6), we will focus on composite mean SHFs and SATs in ASSIM 7-9 years after strong and weak OHT phases. As $\mathrm{HC}$ is initialized in January, we make sure not to average over the initialization by using JFM for winter, AMJ for spring, JAS for summer, and OND for autumn.

We generally find upward SHFs after strong OHT phases at $50^{\circ} \mathrm{N}$ and downward SHFs after weak OHT phases at $50^{\circ} \mathrm{N}$ (Figs. $7 \mathrm{a}-\mathrm{j}$ ). SHFs are strong in winter and fall after both strong and weak OHT phases at 

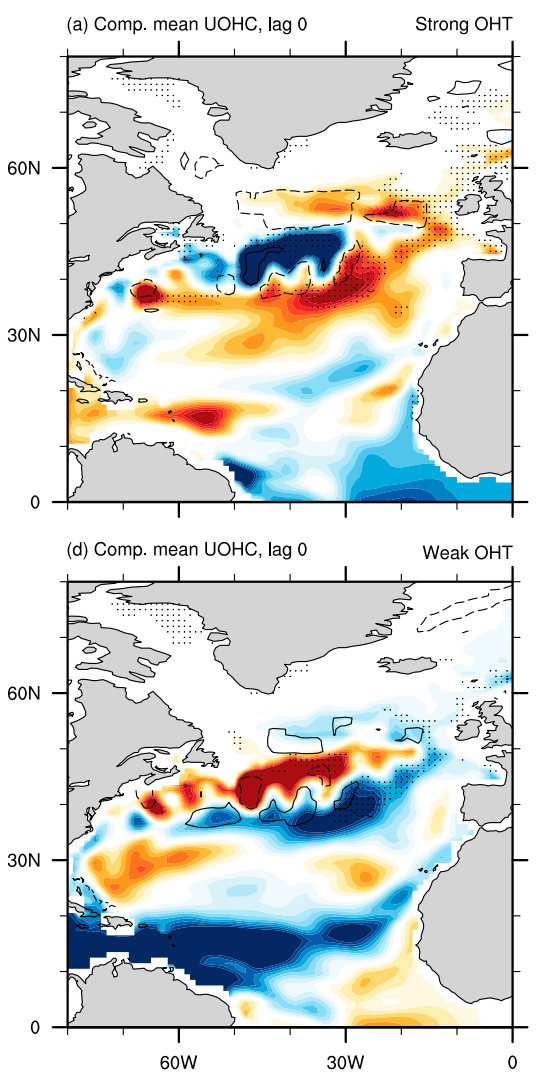

(b) Comp. mean UOHC, OHT lead 3-5yr Strong OHT
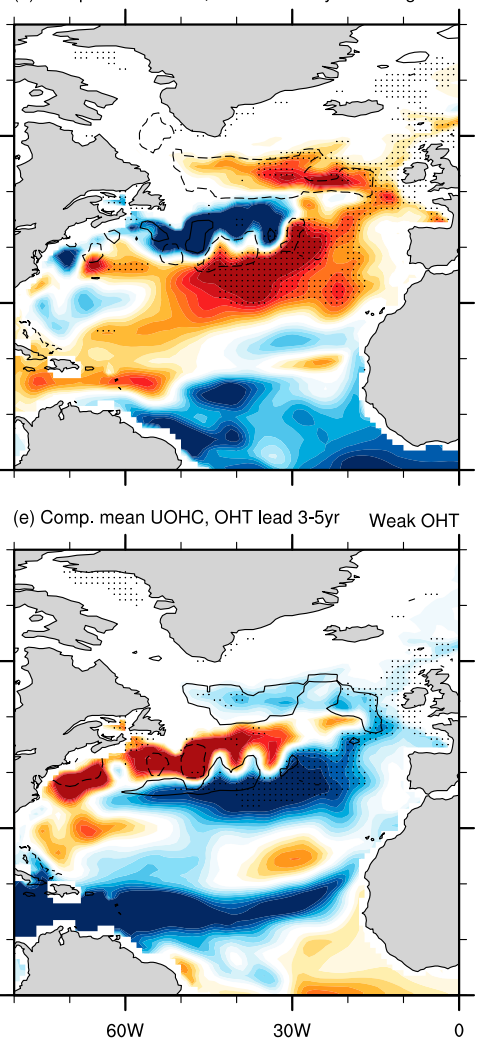

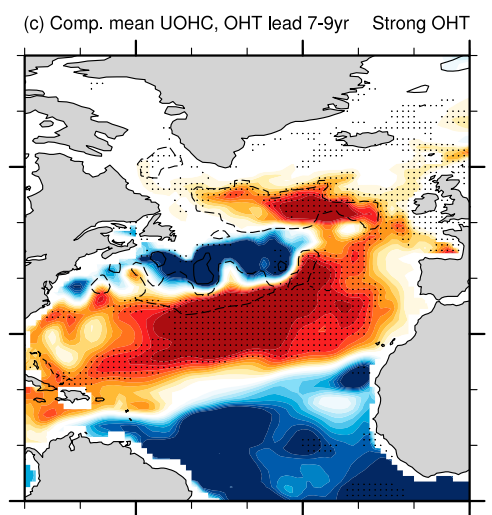

(f) Comp. mean UOHC, OHT lead 7-9yr Weak OHT

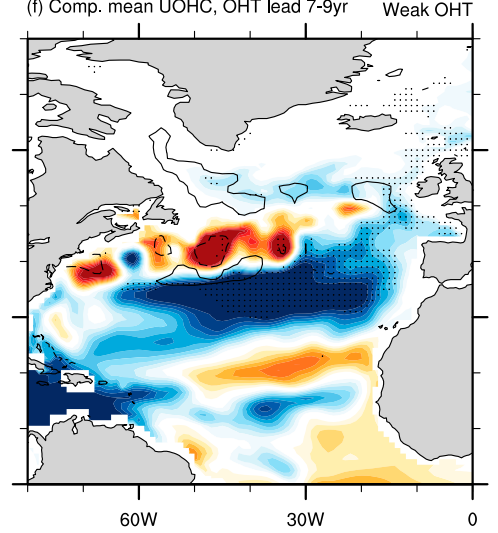

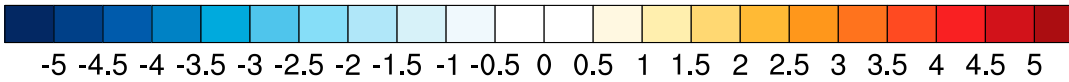

FIG. 5. Composite mean upper-ocean heat content anomalies (PW) in ASSIM, related to (a)-(c) strong and (d)-(f) weak OHT phases at $50^{\circ} \mathrm{N}$. We show composites at (a),(d) lag 0 and composite mean UOHC (b),(e) 3-5 years and (c),(f) 7-9 years after strong and weak OHT phases at $50^{\circ}$ N. Stippling indicates significance at the $99 \%$ level. Contours show significant (at the $99 \%$ level) net ocean-atmosphere surface heat fluxes into the ocean (solid contours) and out of the ocean (dashed contours).

$50^{\circ} \mathrm{N}$, and after strong $\mathrm{OHT}$ phases at $50^{\circ} \mathrm{N}$ in spring (Figs. 7b,c,e,g,j). We do find the zonal asymmetry we found on annual mean SHFs (cf. Fig. 6) with strong SHFs toward the western North Atlantic after strong OHT phases and toward the eastern North Atlantic after weak OHT phases in winter, spring, and fall as well (Figs. 7b,c,e,g,h,j). These findings indicate that low-frequency variability from the ocean is transported into the atmosphere most strongly in winter, spring, and fall, influencing SATs.

In fact, we find strong and significant annual mean SAT anomalies over both the ocean, northern Africa, and parts of northern Europe to be connected to strong and weak OHT phases at $50^{\circ} \mathrm{N}$ (Figs. 7k,p). Asymmetries of composite annual mean SATs between strong and weak OHT phases, which would indicate a dependence of SAT variability on the phase of OHT, are located over the area of the characteristic SST pattern, western Africa, the United Kingdom, and parts of the Iberian Peninsula-these areas show stronger annual mean SAT anomalies after strong OHT phases.
The response of seasonal SATs is generally symmetric between strong and weak OHT phases at $50^{\circ} \mathrm{N}$ over land (Figs. 7l-o, $\mathrm{q}-\mathrm{t}$ ). There are some exceptions: in winter, SATs over Scandinavia show strong anomalies after both strong and weak OHT phases; however, the anomalies are only significantly different from the mean variability after weak OHT phases at $50^{\circ} \mathrm{N}$. In summer, SAT anomalies are significant over Scandinavia after weak OHT phases, and significant over large parts of western Europe and the United Kingdom after strong OHT phases of OHT. The large areas of strong but insignificant wintertime SAT anomaly around Scandinavia indicate high overall temperature variability in that season and area-this is likely related to the impact of the winter North Atlantic Oscillation (e.g., Visbeck et al. 2001). As we find little connection of SHF and SAT anomalies of the same season, there likely is a seasonal lag in the influence of SHF anomalies on SAT variability over Europe (e.g., Czaja and Frankignoul 2002).

On the decadal time-scale time, any SAT signal is likely to be modulated by the ocean. The analyses presented 

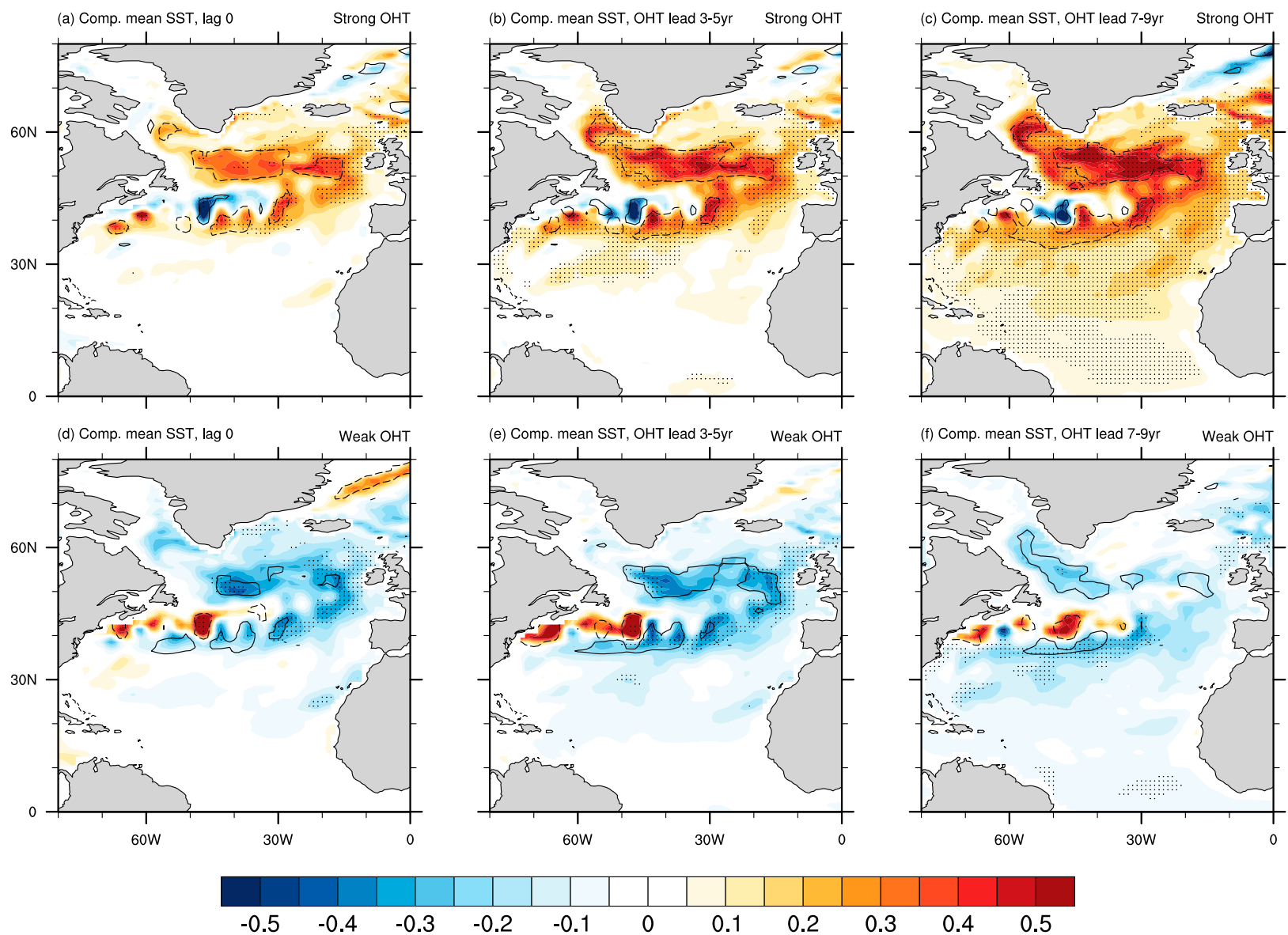

FIG. 6. Composite mean SST anomalies (K) in ASSIM, related to (a)-(c) strong and (d)-(f) weak OHT phases at $50^{\circ} \mathrm{N}$. We show composites at (a),(d) lag 0 and composite mean SSTs (b),(e) 3-5 years and (c),(f) 7-9 years after strong and weak OHT phases at 50 ${ }^{\circ} \mathrm{N}$. Stippling indicates significance at the $99 \%$ level. Contours show significant (at the $99 \%$ level) net ocean-atmosphere surface heat fluxes into the ocean (solid contours) and out of the ocean (dashed contours).

above inspire confidence that there is an influence of the mechanism leading to the characteristic SST pattern on interannual-to-decadal UOHC, SST, SHF, and SAT predictability. We now explore this influence using the dynamical $\mathrm{HC}$ simulations.

\section{Predictability analysis}

Building on the connection between $\mathrm{OHT}$ at $50^{\circ} \mathrm{N}$, UOHC, SSTs, SHFs, and SATs we diagnose above, we investigate whether and how predictability of these parameters on the interannual-to-decadal time scale, so $3-$ 5 years and 7-9 years ahead (at lead years 3-5 and 7-9), depends on the strength of the $\mathrm{OHT}$ at $50^{\circ} \mathrm{N}$ at the initialization of the prediction. We evaluate $\mathrm{HC}$ against ASSIM using ACCs for the entire time series and after strong and weak OHT phases at $50^{\circ} \mathrm{N}$ to connect predictability to the physical mechanism leading to the characteristic SST pattern.
For 1901-2010, we find upper-ocean heat content to be significantly predictable in the entire North Atlantic at lead year 1 with particularly high ACCs in the northeast Atlantic (Fig. 8a). At lead years 3-5 and 7-9, we find significant ACCs for UOHC in the northeast Atlantic as well (Figs. 8b,c). Similarly, SSTs show significant and high ACCs in the northeast Atlantic at lead years 1, 3-5, and 7-9 (Figs. 8d-f). The spatial structure of both UOHC and SST ACCs at lead years 3-5 and 7-9 resemble the shape of the characteristic SST pattern (cf. Fig. 3) and the composite mean UOHC and SST patterns we discuss above (cf. Figs. 5, 6). This indicates that $\mathrm{OHT}$ anomalies at $50^{\circ} \mathrm{N}$ play an important role in modulating UOHC and SST predictability.

\section{a. Predictability of UOHC and SSTs after strong and weak $O H T$ phases at $50^{\circ} \mathrm{N}$}

When analyzing ACCs of UOHC in the North Atlantic for hindcasts started in years of strong (Figs. 9a-c) and weak (Figs. 9d-f) $\mathrm{OHT}$ at $50^{\circ} \mathrm{N}$ separately, we find 

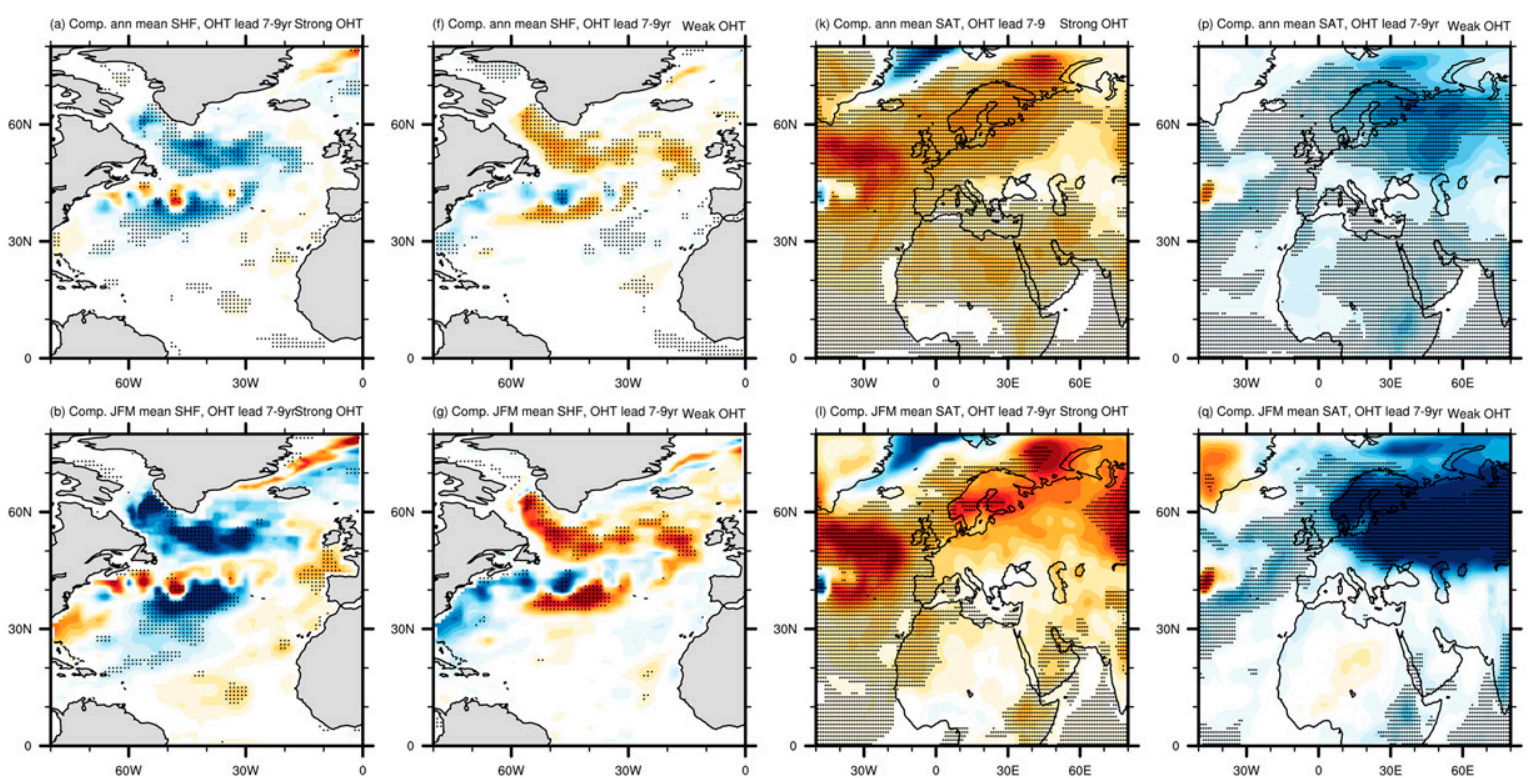

0.45
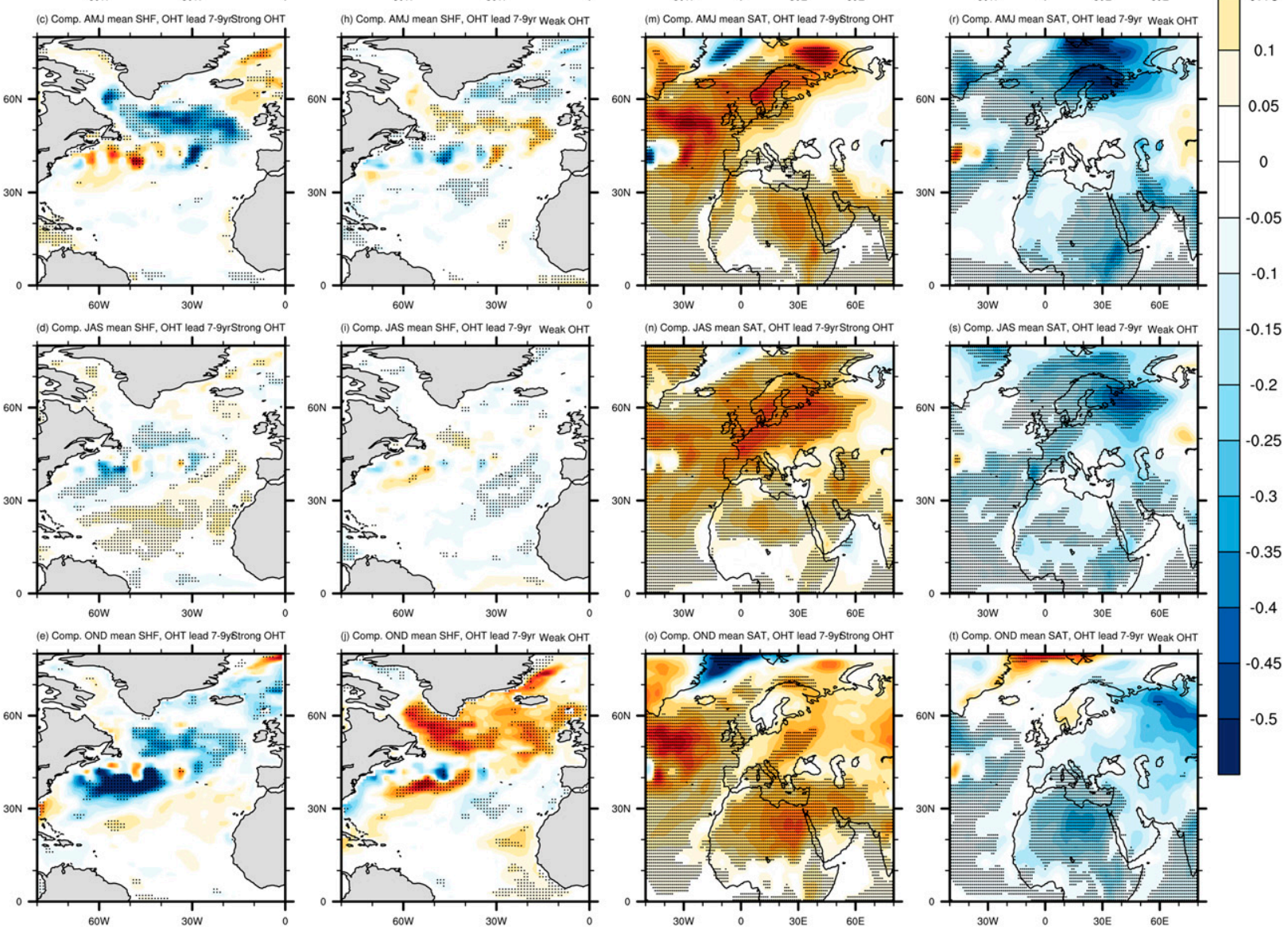

FIG. 7. Composite mean SHFs $\left(\mathrm{W} \mathrm{m}^{-2}\right)$ in ASSIM when (a)-(e) strong and (f)-(j) weak OHT phases at $50^{\circ} \mathrm{N}$ lead by $7-9$ years, and composite mean SAT anomalies (K) in ASSIM when $(\mathrm{k})-(\mathrm{o})$ strong and $(\mathrm{p})-(\mathrm{t})$ weak OHT phases at $50^{\circ} \mathrm{N}$ lead by $7-9$ years. (from top to bottom) We show composites for annual, JFM, AMJ, JAS, and OND means. Stippling indicates significance at the $90 \%$ level. 

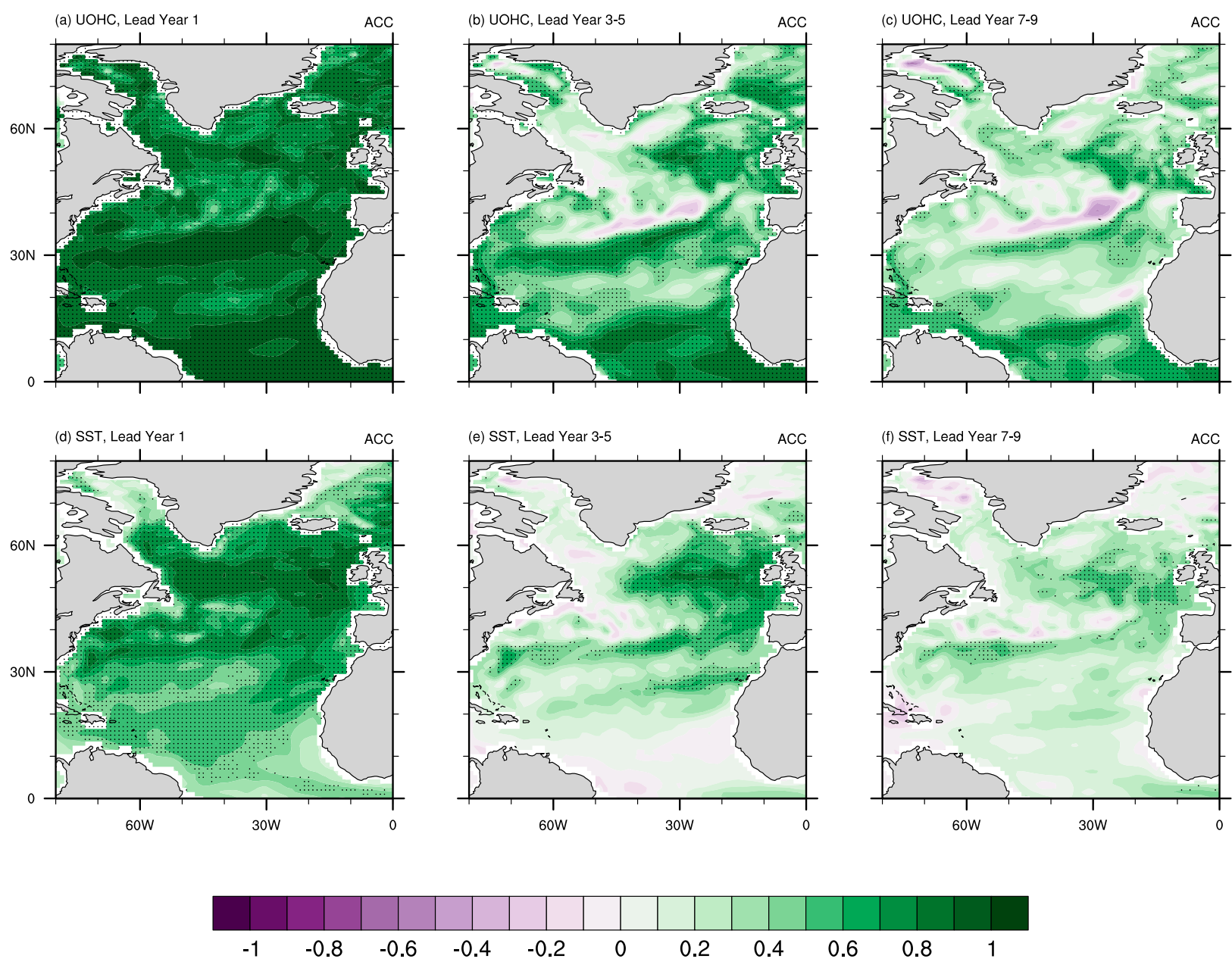

FIG. 8. ACCs of UOHC (upper $700 \mathrm{~m}$ ) from the HC experiments against ASSIM at lead years (a) 1, (b) 3-5, and (c) 7-9. We show ACCs for SSTs at lead years (d) 1, (e) 3-5, and (f) 7-9. Stippling indicates significant ACCs at the 99\% level.

significant UOHC ACCs at all lead years after both strong and weak $\mathrm{OHT}$ anomalies at $50^{\circ} \mathrm{N}$. At lead year 1 , ACCs are very similar after strong and weak OHT phases at $50^{\circ} \mathrm{N}$, and for the entire time series (Figs. 9a,d; 8a). At lead years 3-5 and 7-9, ACCs are generally higher after both strong and weak phases of OHT at $50^{\circ} \mathrm{N}$ than for the entire time series. However, we find highly significant ACCs in large parts of the northeast Atlantic after strong OHT phases at $50^{\circ} \mathrm{N}$ (Figs. 9b,c), while ACCs are significant in the central North Atlantic after weak $\mathrm{OHT}$ phases at $50^{\circ} \mathrm{N}$ (Figs. 9e,f). Other areas of significant UOHC ACCs at longer lead years, such as the area south of the Gulf Stream front and the tropical Atlantic, show little to no asymmetry between strong and weak $\mathrm{OHT}$ phases at $50^{\circ} \mathrm{N}$.

ACCs of SSTs behave very similar to ACCs of UOHC. SST ACCs are significant at all lead years after both strong and weak OHT phases at $50^{\circ} \mathrm{N}$ (Fig. 10). At lead year 1 they are similar to ACCs diagnosed for the entire time series (Figs. 10a,d; 8d). At lead years 3-5 and 7-9, we find significant ACCs of SSTs to be higher and to cover larger areas after strong than after weak OHT phases at $50^{\circ} \mathrm{N}$ (Figs. 10b,c,e,f). Again, we find a zonal difference in ACCs between strong and weak OHT phases at $50^{\circ} \mathrm{N}$, with significant ACCs in the northeast Atlantic after strong OHT phases at $50^{\circ} \mathrm{N}$ and more centrally located significant ACCs after weak OHT phases at $50^{\circ} \mathrm{N}$. Other areas of significant ACCs for SSTs do not show much asymmetry between strong and weak OHT phases at $50^{\circ} \mathrm{N}$. This agrees with our findings from the UOHC predictability study and suggests that the influence of $\mathrm{OHT}$ at $50^{\circ} \mathrm{N}$ on predictability changes of UOHC and SSTs in those areas is limited.

The zonal asymmetry we find between the ACC patterns of both UOHC and SSTs at lead years 7-9 after strong and weak OHT phases at $50^{\circ} \mathrm{N}$ can be attributed to the zonally asymmetric significant composite mean 

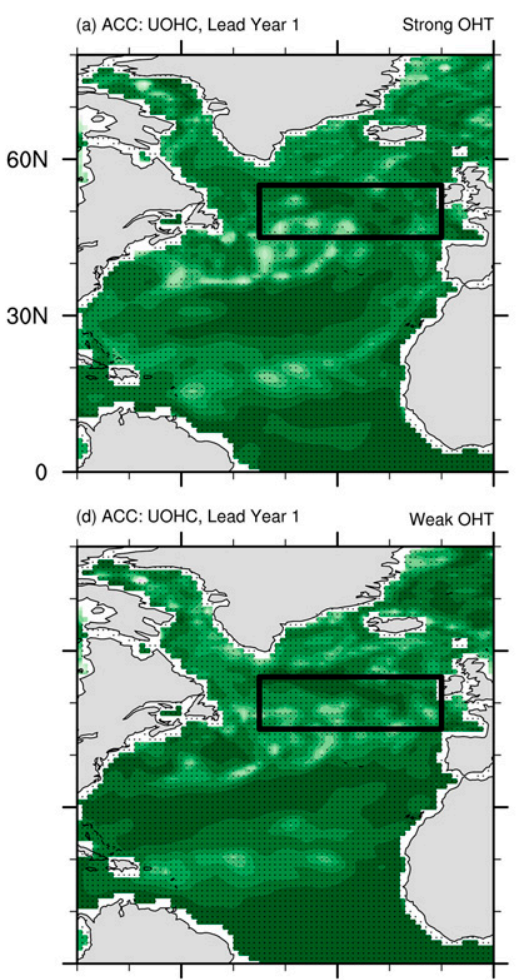
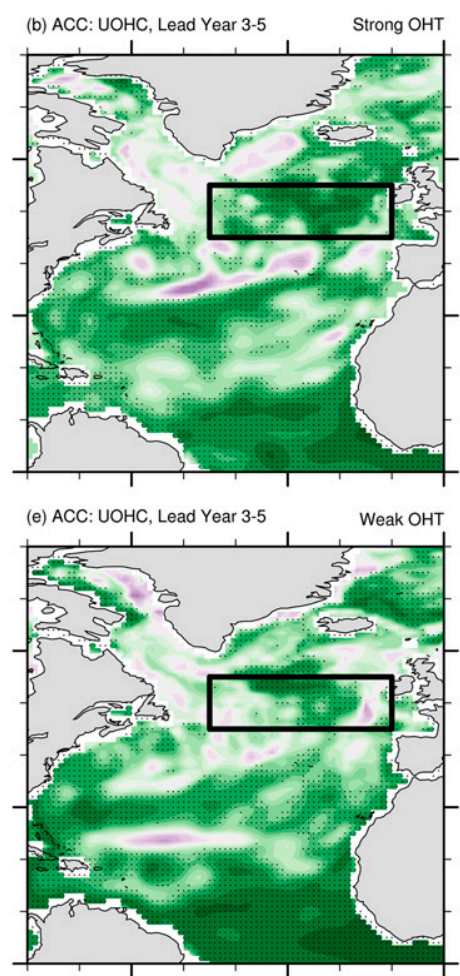

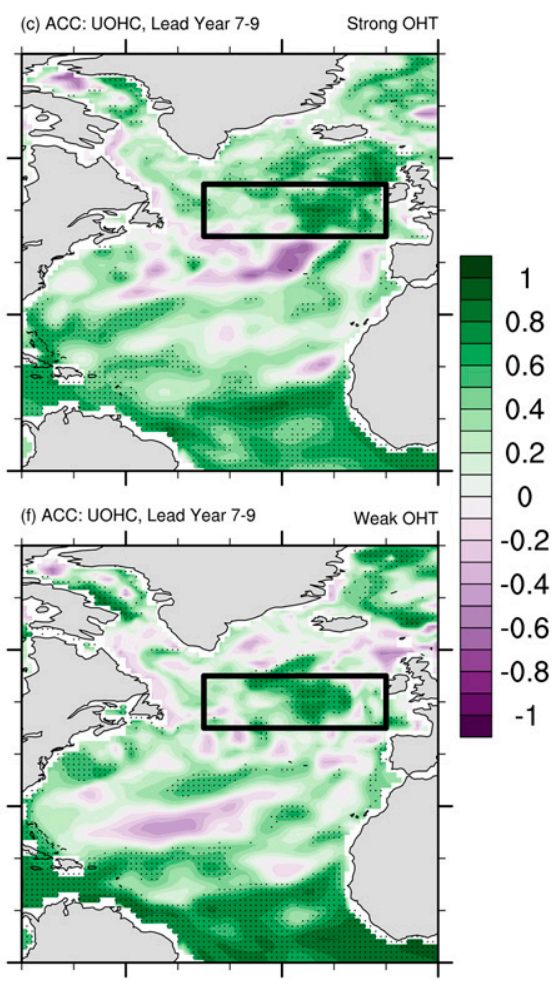

FIG. 9. Upper-ocean heat content (upper $700 \mathrm{~m}$ ) ACCs from our HC experiments against ASSIM after (a)-(c) strong and (d)-(f) weak OHT phases at $50^{\circ} \mathrm{N}$. We show ACCs at lead years (a),(d) 1; (b),(e) 3-5; and (c),(f) 7-9. Stippled areas indicate significant ACCs at the $99 \%$ level. The black box is the area that UOHC is averaged over for Fig. 11a.

SHFs we show in Figs. 5 and 6. After both strong and weak $\mathrm{OHT}$ phases at $50^{\circ} \mathrm{N}$ we find predictable UOHC and SSTs in areas that are characterized by little heat exchange with the atmosphere. This is an indication that significant ACCs are indeed connected to low-frequency ocean dynamics and that they break down where the atmosphere contributes significantly to surface temperature variability.

To further illustrate the overall effect of strong and weak OHT phases at $50^{\circ} \mathrm{N}$ on interannual-to-decadal predictability of UOHC and SSTs, we show in Fig. 11 ACCs for average UOHC and SSTs in the northeast Atlantic $\left(45^{\circ}-55^{\circ} \mathrm{N}, 45^{\circ}-10^{\circ} \mathrm{W}\right.$, cf. black box in Figs. 9 and 10). Note that this area covers locations where we find significant predictability of UOHC and SSTs after both strong and weak OHT phases at $50^{\circ} \mathrm{N}$. ACCs evaluated over the entire time series for both UOHC and SSTs are generally high in the northeast Atlantic for up to 9 lead years and outperform persistence forecast at lead years $>1$ (Fig. 11). After strong OHT phases at $50^{\circ} \mathrm{N}$, ACCs in the northeast Atlantic are significantly higher than after weak OHT phases at $50^{\circ} \mathrm{N}$ and for the entire time series at lead years 2-7 for UOHC (Fig. 11a) and 2-9 for SST (Fig. 11b), as shown by nonoverlapping interquartile ranges plotted around the mean ACCs.
Similarly, we find ACCs for UOHC after weak OHT phases at $50^{\circ} \mathrm{N}$ that are significantly lower than ACCs after strong OHT phases and for the entire time series for lead years $2-6$. This can be partly explained by the comparatively small area in which we find high ACCs for $\mathrm{UOHC}$ after weak OHT phases at $50^{\circ} \mathrm{N}$. After lead year 7 we find a reemergence of UOHC ACCs but not for SSTs (Fig. 11). A possible reason for this could be decadal UOHC trends in the subpolar North Atlantic. This analysis provides further indication that the mechanism leading to the characteristic SST pattern influences UOHC and SST predictability on the interannual-todecadal time scale. We explore next whether a similar conclusion can be drawn for dynamical predictions of annual and seasonal mean SHFs and SATs.

\section{b. SHF and SAT predictability}

ACCs are high for seasonal mean SHFs at lead years 7-9 in areas where ACCs are high for SSTs at the same lead time after both strong and weak OHT phases at $50^{\circ} \mathrm{N}$ (Figs. 12a-j; cf. Figs. 10c,f). Specifically, SHF ACCs are high in the northeast Atlantic after strong OHT phases, and they are high in the central North Atlantic after weak OHT phases at $50^{\circ} \mathrm{N}$. ACCs for SHFs are significant in the North Atlantic in spring after strong $\mathrm{OHT}$ at $50^{\circ} \mathrm{N}$ 

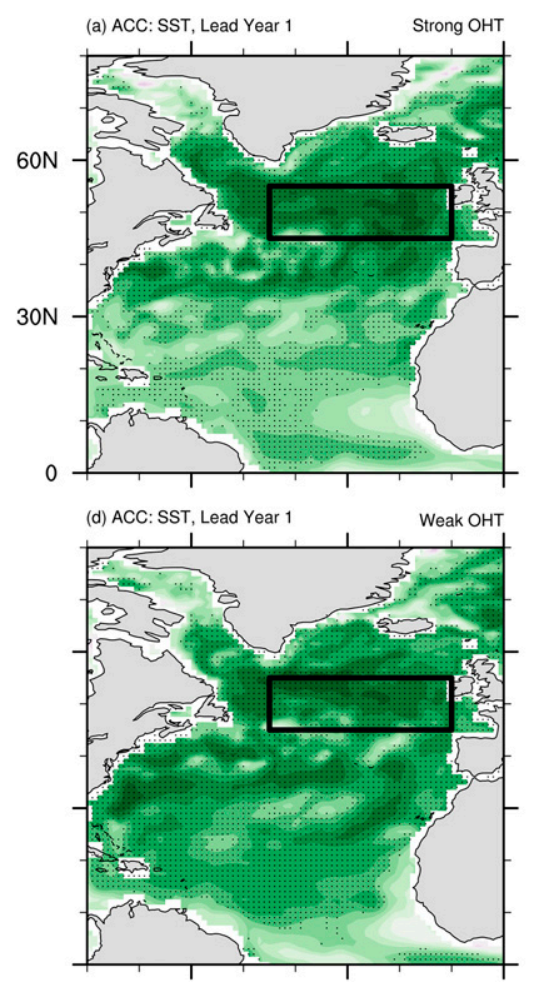
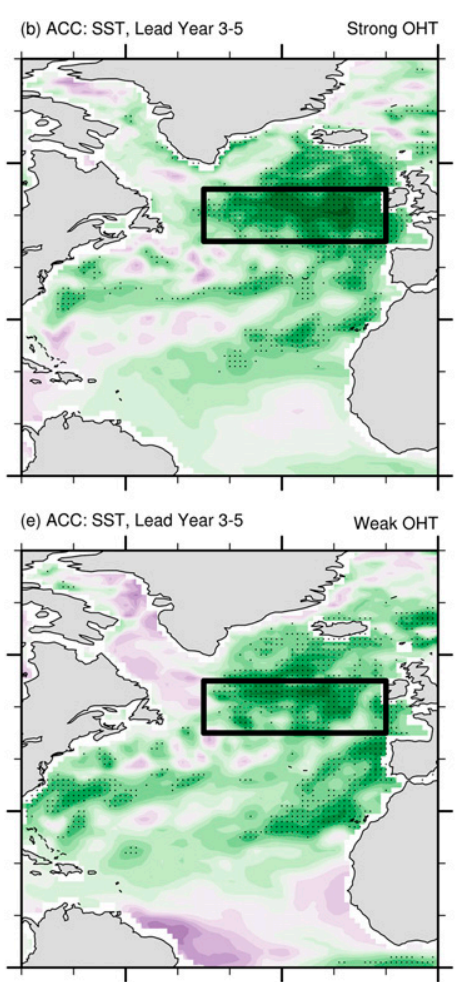

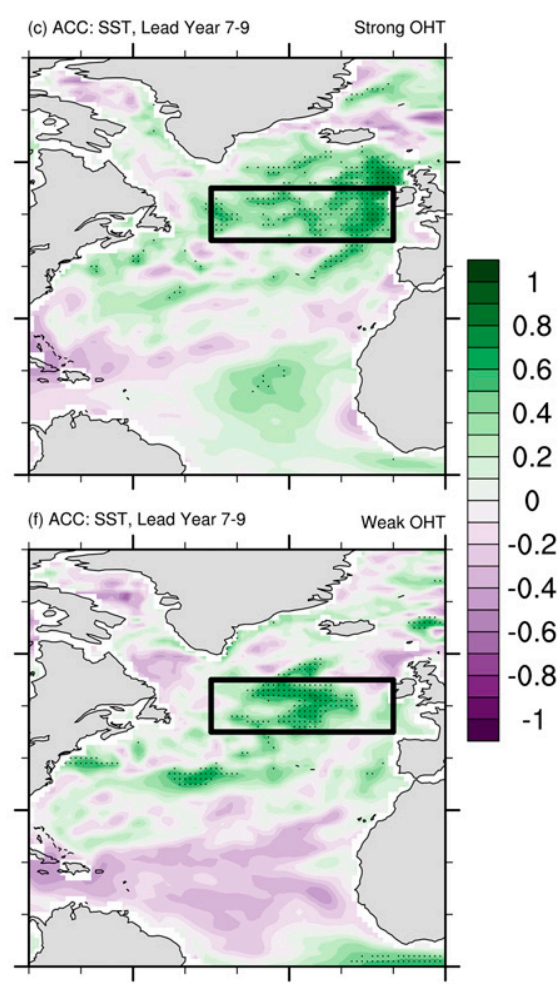

FIG. 10. SST ACCs from HC against ASSIM after (a)-(c) strong and (d)-(f) weak OHT phases at $50^{\circ} \mathrm{N}$. We show ACCs at lead years (a),(d) 1; (b),(e) 3-5; and (c),(f) 7-9. Stippled areas indicate significant ACCs at the $99 \%$ level. The black box is the area that SSTs are averaged over for Fig. 11b.

(Fig. 12c). In all other seasons, ACCs for SHFs are largely insignificant following both strong and weak OHT at $50^{\circ} \mathrm{N}$. Following the assumption that SAT ACCs of decadal hindcasts are modulated by the ocean, this suggests that there could be limited ACCs for SAT hindcasts at seasonal means in HC, because the predictable SST signal is only in spring transported into the atmosphere.

ACCs are only marginally significant for seasonal mean SATs over land at lead years 7-9 after strong and weak OHT phases at $50^{\circ} \mathrm{N}$ (Figs. $12 \mathrm{k}-\mathrm{t}$ ). The shape of these ACCs also bears little resemblance to the composite mean SAT patterns we identified before (cf. Fig. 7). There is some seasonal variability in SAT ACCs, but this appears to not be linked to SHF predictability. Specifically, we find high ACCs for SATs over the ocean across all seasons, while ACCs are generally low over land. The shape of these ACCs generally resembles that of predictable SSTs. This illustrates that in HC, the influence of North Atlantic OHT variability on SAT hindcasts is limited to the areas that are immediately influenced by the ocean. However, the predictability of SHFs does not play a role in the prediction of SATs. HC does apparently not properly represent teleconnection mechanisms that could transport SST anomalies to Europe at both annual and seasonal means.

\section{Discussion}

The results presented in this study are generally in line with previously published studies of interannual-todecadal predictions of North Atlantic surface temperatures (e.g., Matei et al. 2012; Robson et al. 2013, 2014; Müller et al. 2014). We show that the suggestion of Zhang and Zhang (2015) that the ocean heat transport in the North Atlantic modulates SST predictability has merit. However, some of our findings require discussion, like the model specificity of our findings, the contribution of strong and weak OHT phases to SST variability, the role of ocean-atmosphere surface heat fluxes, the role of Atlantic multidecadal variability (AMV) in our findings, and the missing skill in dynamical surface air temperature predictions. We further want to highlight consequent implications of the findings presented in this study.

A major caveat of the results we present here is the use of three ensemble members of just one model. The small ensemble size was previously shown to be appropriate to study North Atlantic climate variability and predictability (Müller et al. 2014, 2015). Especially in the predictability analysis, the length of the model experiments we use makes up for at least some of the uncertainty introduced by the limited ensemble size. To 
(a) ACC: avg. UOHC $(45-55 \mathrm{~N}, 10-45 \mathrm{~W})$

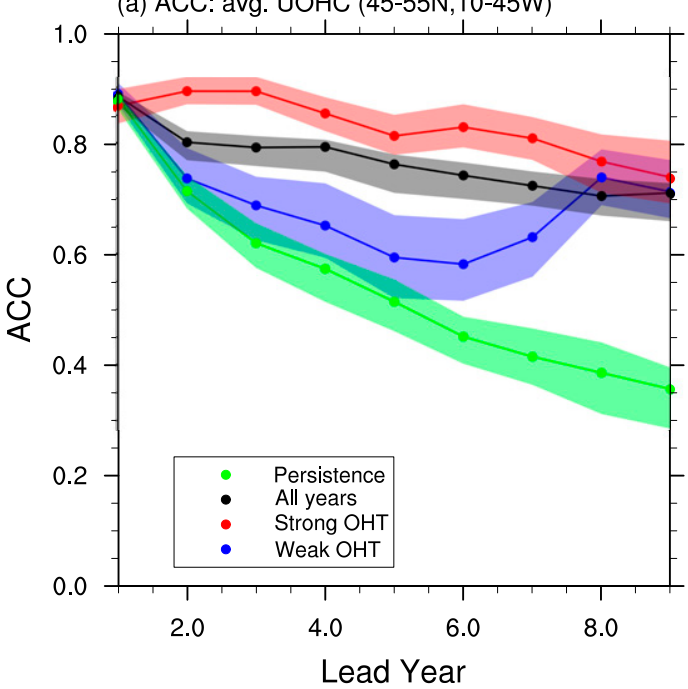

(b) ACC: avg. SST $(45-55 \mathrm{~N}, 10-45 \mathrm{~W})$

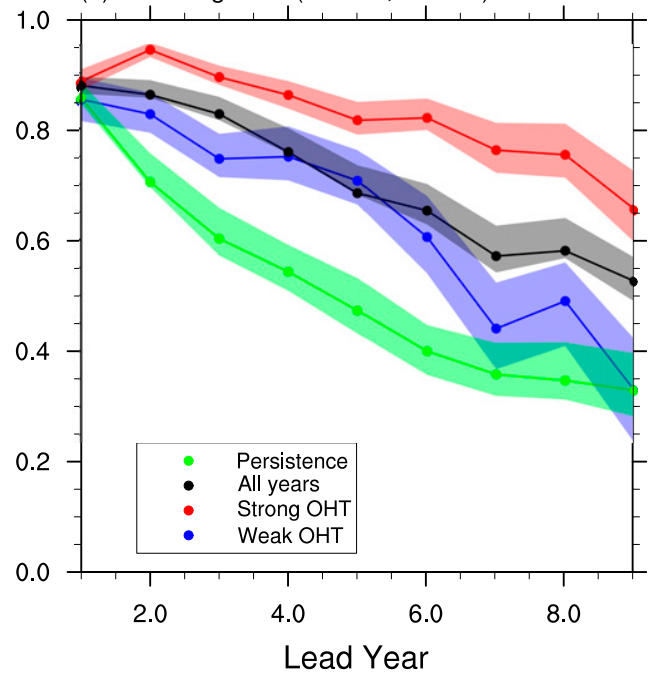

FIG. 11. ACCs for average (a) UOHC and (b) SSTs over the box indicated in Figs. 9 and 10 against lead time. We use ASSIM as a reference. The black line shows ACCs over the entire time series, green shows persistence forecast, the blue line shows predictability after weak, and the red line shows predictability after strong OHT phases at $50^{\circ} \mathrm{N}$. The shaded areas indicate the interquartile ranges around the mean predictability for each color. Solid points represent ACCs significant at the $99 \%$ level.

some degree, our findings have to be interpreted as model specific, though. In particular, we find an eastward displacement of the characteristic SST pattern that is connected to OHT variability compared to Zhang and Zhang (2015), while finding a very similar dynamical explanation for the origin of the characteristic SST pattern as Zhang and Zhang (2015). This indicates that the MPI-ESM-LR reacts similarly to OHT anomalies in the North Atlantic as the GFDL CM2.1 used in Zhang and Zhang (2015), but these anomalies affect a different area in the North Atlantic. The more eastward characteristic SST pattern we find could indicate a more zonal Gulf Stream in the MPI-ESM compared to the GFDL model-in that case, the use of a higher-resolution model might alleviate this problem. An evaluation of HC against HadISST observations (Rayner et al. 2003) shows little skill in the North Atlantic because of a more westward characteristic SST pattern in HadISST than in the MPI-ESM-LR (not shown); consequently, we evaluate hindcast performance against the assimilation experiment. This study therefore shows the evolution of the characteristic SST pattern and its influence on interannual-to-decadal predictions of surface temperatures in an internally consistent initialized model world. Because the physical mechanism leading to the predictability patterns we identify here is consistent with previous publications, the conclusion that OHT in the North Atlantic influences SST predictability in the way we describe above-probably somewhat farther to the west-is valid.
We find different length of strong and weak OHT phases at $50^{\circ} \mathrm{N}$ (cf. Fig. 1). Although the quantities of years of strong and weak $\mathrm{OHT}$ at $50^{\circ} \mathrm{N}$ as identified by the criterion we define are similar (weak OHT: 36 years; strong OHT: 40 years), strong OHT phases appear more coherently than weak ones. This might affect the composite mean analysis we conduct, as longer OHT phases might also have a more pronounced impact on SSTs. However, because the time horizon of assimilation experiments and therefore the initialization of dynamical hindcasts are limited by the length of reanalysis, and the whole point of this study are dynamical hindcasts, we accept this caveat for now and suggest a more detailed study on this effect for the future.

We find that, for both UOHC and SSTs, predictability is connected to the physical mechanism leading to the characteristic SST pattern. An exception from this result is the Labrador Sea, which is covered by the characteristic SST pattern but where we find no predictability. This effect can be attributed to the incapability of the free MPI-ESM-LR to represent temperature variability in the Labrador Sea (e.g., Brune et al. 2017) and stronger surface heat fluxes in that area that overwrite the predictable temperature signal in the ocean (cf. Fig. 6). As a result, predictability is lost faster in the Labrador Sea than elsewhere in the North Atlantic.

An analysis of the influence of the persistence of $\mathrm{UOHC}$ on UOHC and SST predictability in the northeast Atlantic region analog to the analysis shown in Fig. 11 reveals that both UOHC and SST prediction skill 

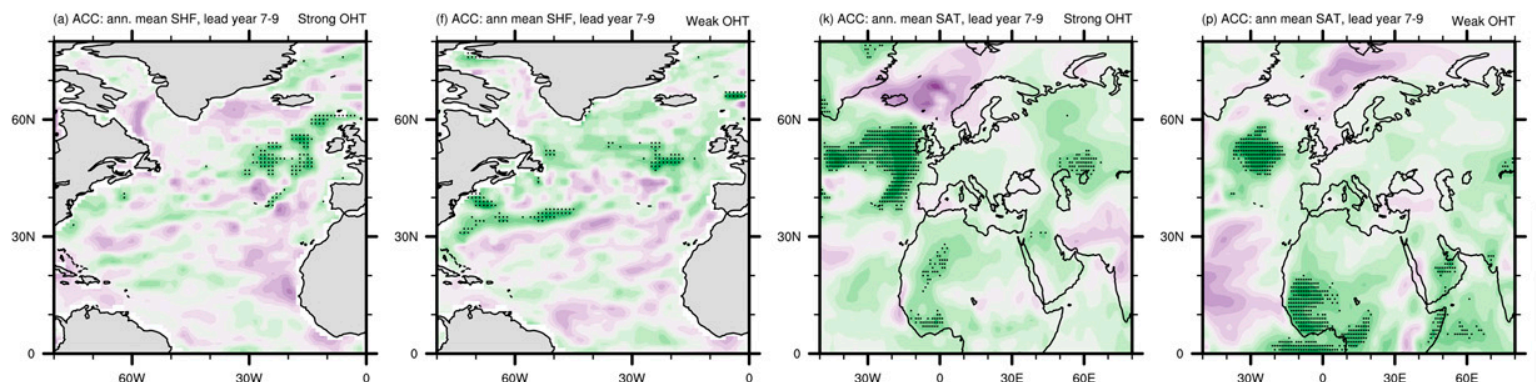

1
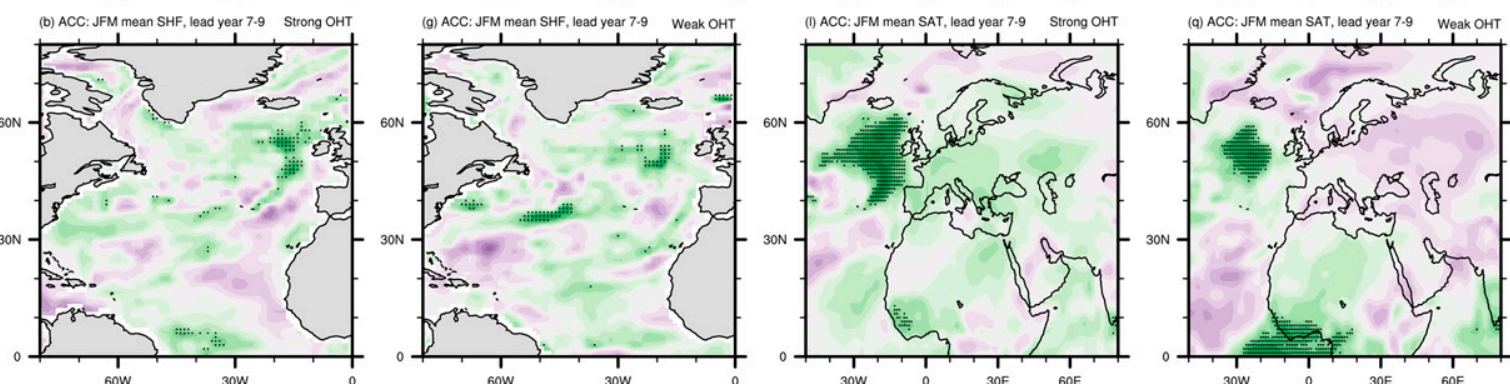

0.9
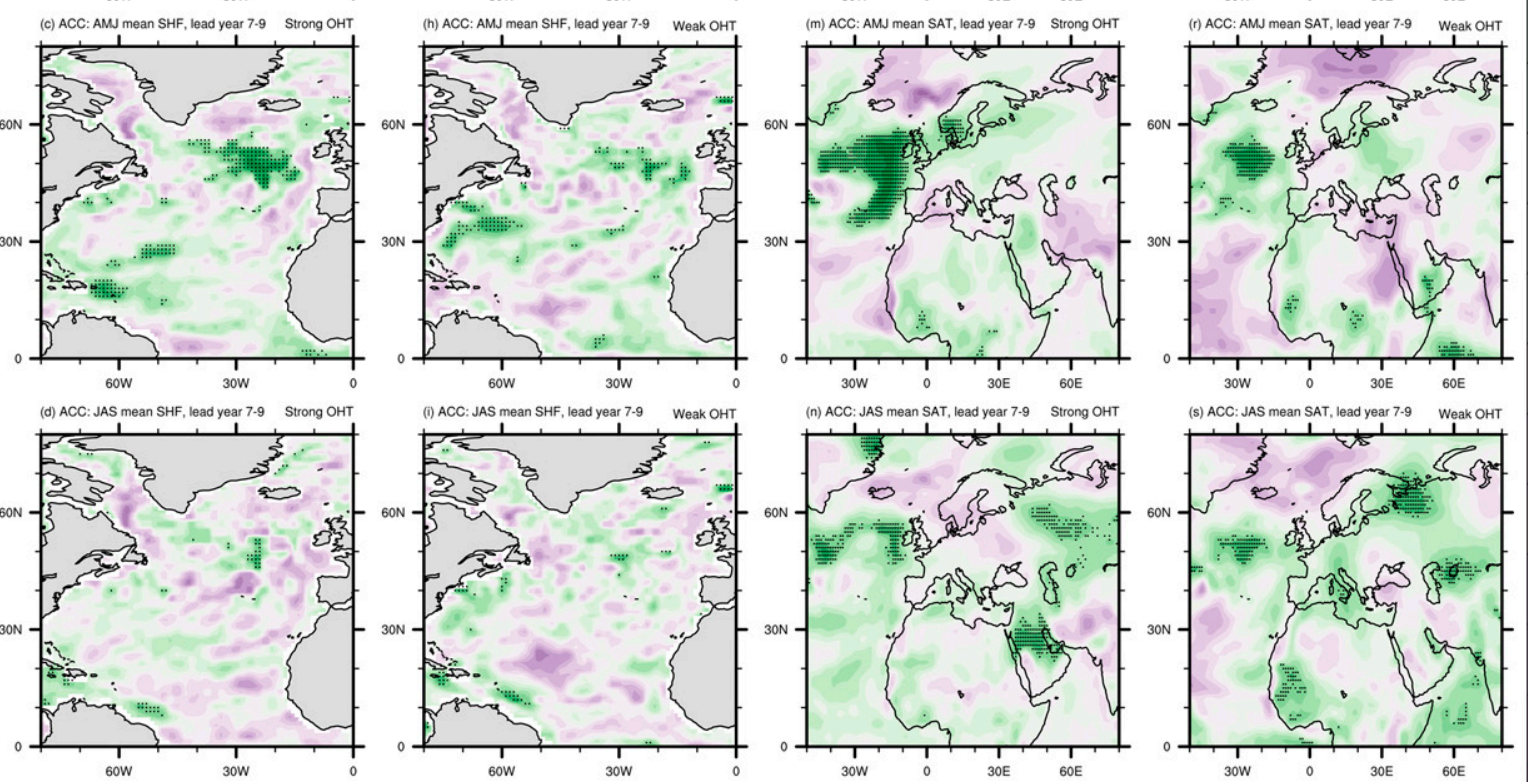

0.8
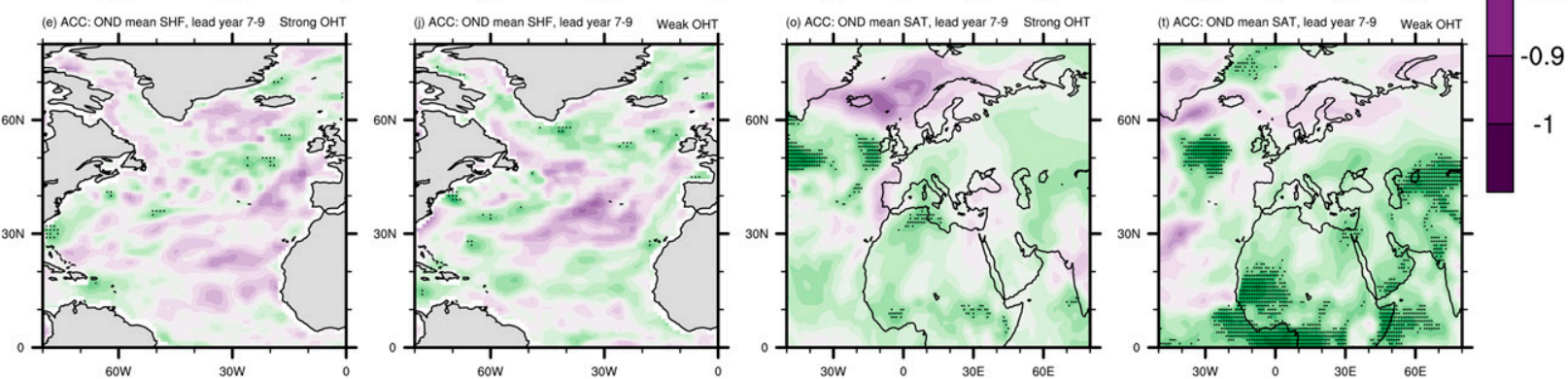

FIG. 12. ACCs at lead years 7-9 from HC against ASSIM for SHFs after (a)-(e) strong and (f)-(j) weak OHT phases at 50 N, and SAT ACCs after $(\mathrm{k})-(\mathrm{o})$ strong and $(\mathrm{p})-(\mathrm{t})$ weak OHT phases at $50^{\circ} \mathrm{N}$. (from top to bottom) We use annual, JFM, AMJ, JAS, and OND means. Stippling indicates significance at the $99 \%$ level. 


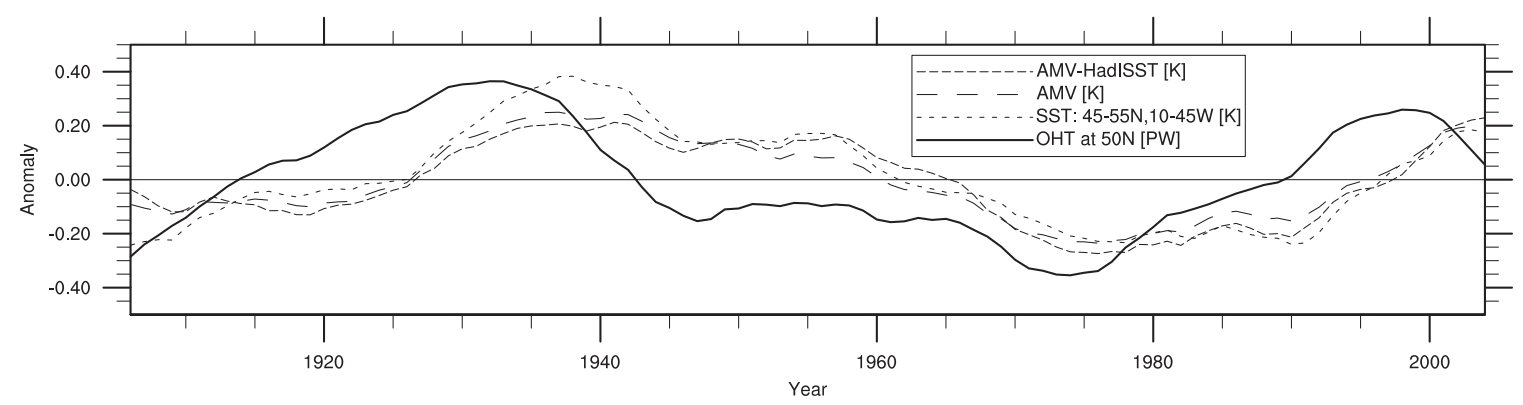

FIG. 13. Time series from ASSIM of OHT anomalies at $50^{\circ} \mathrm{N}$ (solid line, PW), mean temperature anomalies in the box indicated in Figs. 9 and 10 (stippled line, K), and AMV as defined as average SST anomalies between $0^{\circ}$ and $60^{\circ} \mathrm{N}$ in the North Atlantic (dashed line, $\mathrm{K})$. We also show the AMV time series from HadISST observations (K) in narrow dashes. Time series are low-pass filtered with an 11-yr running mean.

during and after phases of high $\mathrm{UOHC}$ is similar to that for the entire time series (not shown). During and after low UOHC, skill is generally low and decreases into insignificance by lead years 4 (UOHC) and 5 (SST). Thus, prediction skill after weak OHT phases at $50^{\circ} \mathrm{N}$ is higher than that during and after low $\mathrm{UOHC}$, but the positive influence of strong phases of $\mathrm{OHT}$ at $50^{\circ} \mathrm{N}$ on UOHC and SST prediction skill in the northeast Atlantic is stronger than that from UOHC persistence. This indicates that some level of heat stored in the upper ocean is necessary for decadal UOHC and SST prediction skill, but dynamical processes in the ocean are more important for increasing decadal prediction skill than persistence of UOHC.

Our study generally supports the suggestion by earlier research that temperatures in the eastern North Atlantic are controlled by ocean advection, while temperatures in the western North Atlantic are controlled by surface heat fluxes (e.g., Robson et al. 2018). Our study suggests, however, that this notion depends on the strength of ocean heat transport. When OHT is strong, we find that the northeast Atlantic is strongly influenced by ocean heat advection. During and after weak OHT, SHFs become more important in the modulation of surface temperatures in the northeast Atlantic (Fig. 6).

The AMV is a dominant feature of North Atlantic temperature variability (e.g., Clement et al. 2015; Zhang et al. 2016), which has in the past been hypothesized to play an important role in predictability of North Atlantic temperatures. The mechanism we describe here, as well as the characteristic SST pattern seem to be closely related to the AMV in our model (Fig. 13). This study therefore supports the notion that the AMV is a driver of North Atlantic temperature predictability. OHT at $50^{\circ} \mathrm{N}$ in our study leads the AMV by 8 years (maximum correlation: 0.9), which indicates that the ocean contributes to the formation of the AMV. As a result, the physical mechanism invoked in this study can, beyond its contribution to interannual-to-decadal SST predictability in the northeast Atlantic, be seen as a contributor to AMV predictability on the same time scale [which supports findings presented in Zhang (2017)]. Note that the AMV time series in ASSIM is also closely connected with the AMV in HadISST (Fig. 13), which is an indication that the model used in this study reflects real climate variability in the North Atlantic reasonably well and supports our statement that a lack of SST prediction skill in the North Atlantic, when evaluated against HadISST, is connected to different spatial SST structures in the model and observations.

The influence of the characteristic SST pattern on dynamical surface air temperature predictions on decadal time scales is limited in our study. Arthun et al. (2017) show skill for decadal winter SATs over Scandinavia that is connected to ocean heat transport using observations and a statistical model. We find no dynamical prediction skill in that area (cf. Fig. 12). This lack of skill could be connected to the limited predictability we find for areas of strong SHFs that could transport SST signals into the atmosphere. It could also be an artifact of the limited resolution, non-stratosphere-resolving nature (this would be necessary for the representation of teleconnections), or few ensemble members of the model setup we use [for a recent discussion of dynamic multiyear predictions over land see e.g., Sheen et al. (2017)]. In any case, our results support Arthun et al. (2017) that there appears to be a connection of OHT to Scandinavian SATs (cf. Fig. 7), which could be invoked to improve decadal SAT predictability over Scandinavia in dynamical models using a larger ensemble, more frequent hindcast initialization, or a higher-resolution model that better represents atmospheric variability at all vertical levels.

Brune et al. (2017) show that the estimated skill of decadal surface temperature predictions in the North Atlantic varies depending on the time for which that skill is evaluated. This finding implies that the use of 
any decadal predictions skill estimate-produced for the past-for the estimation of the expected skill of an actual prediction is limited. This study suggests that ocean heat transport in the subpolar North Atlantic could be used as a possible indicator of expected skill of an actual prediction. As there is currently no long-term observational dataset of OHT in the subpolar North Atlantic, this suggestion cannot be currently verified against observations. The Overturning in the Subpolar North Atlantic Program (OSNAP; Lozier et al. 2017) aims to construct such an observational dataset. As it could be used as an indicator for the expected skill of an actual interannual-to-decadal surface temperature prediction in the North Atlantic region, the dataset produced by the OSNAP campaign holds exciting opportunities for the suggestions we bring forward in this study.

\section{Conclusions}

We use three ensemble members of initialized fully coupled MPI-ESM-LR model simulations for the period 1901-2010 (Müller et al. 2014) to explore the influence of the ocean heat transport at $50^{\circ} \mathrm{N}$ on the interannualto-decadal predictability of upper-ocean heat content, sea surface temperatures, ocean-atmosphere surface heat fluxes, and surface air temperatures in the North Atlantic region. We find the following:

- OHT anomalies at $50^{\circ} \mathrm{N}$ influence SST anomalies in the North Atlantic for up to 9 years. This is connected to ocean heat convergence between $45^{\circ}$ and $55^{\circ} \mathrm{N}$ and UOHC anomalies that result from this heat convergence as suggested by Zhang and Zhang (2015). The strength of the influence of OHT phases at $50^{\circ} \mathrm{N}$ on variability and predictability of UOHC, SSTs, and SHFs up to 9 years later depends strongly on the initial strength of OHT at $50^{\circ} \mathrm{N}$. SATs show no strong dependence on OHT. An important limitation of this study is the fact that we find longer-lived phases of strong than of weak OHT at $50^{\circ} \mathrm{N}$, which might make strong OHT phases at $50^{\circ} \mathrm{N}$ appear more impactful.

- Slowly southward-propagating strong phases of OHT at $50^{\circ} \mathrm{N}$ lead to

(i) significant ACCs of UOHC in the northeast Atlantic that persist for up to 9 years, leading to

(ii) an SST anomaly in the northeast Atlantic that shows significant ACCs for up to 9 years where the impact of SHFs is low.

- Slowly southward-propagating weak OHT phases at $50^{\circ} \mathrm{N}$ lead to

(i) significantly smaller UOHC ACCs in the northeast Atlantic than after a strong OHT anomaly at $50^{\circ} \mathrm{N}$ at lead times longer than 1 year. (ii) Similarly, except for lead year 1, SSTs in the northeast Atlantic remain less predictable after weak OHT phases at $50^{\circ} \mathrm{N}$ than after strong OHT phases at $50^{\circ} \mathrm{N}$.

(iii) This effect partly originates from the extent of significant SST ACCs, which is smaller and more westward after weak than after strong OHT phases at $50^{\circ} \mathrm{N}$. This is connected to strong SHF anomalies in the northeast Atlantic after weak OHT phases at $50^{\circ} \mathrm{N}$.

- SST variability in the northeast Atlantic is closely connected to the AMV in both the model and observations, which indicates that the mechanism we invoke in this study contributes to the AMV and likely has implications for its prediction.

- SHFs are generally predictable in areas where they show no significant strength (i.e., where the ocean exchanges little to no heat with the atmosphere). As a consequence, dynamical predictions of SATs shown in this study are barely affected by the phase of the OHT. However, SATs over Scandinavia are affected by OHT at $50^{\circ} \mathrm{N}$, which indicates potential for an influence of OHT at $50^{\circ} \mathrm{N}$ on dynamical SAT predictions.

This study suggests that the interannual-to-decadal predictability of northeast Atlantic SSTs and the AMV depends strongly on the strength of North Atlantic OHT at $50^{\circ} \mathrm{N}$ at the initialization of the hindcast. OHT in the subpolar North Atlantic could therefore be used as an indicator to judge the expected skill of actual surface temperature predictions up to 9 years ahead.

Acknowledgments. We thank three anonymous reviewers for their helpful comments. We further thank Alexander Hudy, Kameswarrao Modali, André Düsterhus, Vimal Koul, and Sebastian Brune for valuable proofreading, technical support, and discussions. This research was supported by the International Max Planck Research School on Earth System Modelling (IMPRS-ESM), Hamburg (LB); the German Ministry of Education and Research (BMBF) under the MiKlip FlexForDec (Grant 01LP1519A; WM); and through the Cluster of Excellence CliSAP (EXC177), Universität Hamburg, funded through the German Science Foundation (DFG; JB). The model simulations were performed at the German Climate Computing Centre (DKRZ). The authors declare no conflict of interest.

\section{REFERENCES}

Arlot, S., and A. Celisse, 2010: A survey of cross-validation procedures for model selection. Stat. Surv., 4, 40-79, https://oi.org/ 10.1214/09-SS054. 
Arthun, M., T. Eldevik, E. Viste, H. Drange, T. Furevik, H. L. Johnson, and N. S. Keenlyside, 2017: Skillful prediction of northern climate provided by the ocean. Nat. Commun., 8 , 15875, https://doi.org/10.1038/ncomms15875.

Branstator, G., and H. Teng, 2010: Two limits of initial-value decadal predictability in a CGCM. J. Climate, 23, 6292-6311, https://doi.org/10.1175/2010JCLI3678.1.

Brune, S., A. Düsterhus, H. Pohlmann, W. A. Müller, and J. Baehr, 2017: Time dependency of the prediction skill for the North Atlantic subpolar gyre in initialized decadal hindcasts. Climate Dyn., https://doi.org/10.1007/ s00382-017-3991-4, in press.

Clement, A., K. Bellomo, L. N. Murphy, M. A. Cane, T. Mauritsen, G. Radel, and B. Stevens, 2015: The Atlantic Multidecadal Oscillation without a role for ocean circulation. Science, $\mathbf{3 5 0}$, 320-324, https://doi.org/10.1126/science.aab3980.

Collow, T. W., W. Wang, A. Kumar, and J. Zhang, 2015: Improving Arctic sea ice prediction using PIOMAS initial sea ice thickness in a coupled ocean-atmosphere model. Mon. Wea. Rev., 143, 4618-4630, https://doi.org/10.1175/ MWR-D-15-0097.1.

Compo, G. P., and Coauthors, 2011: The Twentieth Century Reanalysis Project. Quart. J. Roy. Meteor. Soc., 137, 1-28, https:// doi.org/10.1002/qj.776.

Czaja, A., and C. Frankignoul, 2002: Observed impact of Atlantic SST anomalies on the North Atlantic Oscillation. J. Climate, 15, 606-623, https://doi.org/10.1175/1520-0442(2002)015<0606: OIOASA $>2.0 . \mathrm{CO} ; 2$.

Doblas-Reyes, F. J., and Coauthors, 2013: Initialized near-term regional climate change prediction. Nat. Commun., 4, 1715, https:// doi.org/10.1038/ncomms2704.

Dong, S., S. L. Hautala, and K. A. Kelly, 2007: Interannual variations in upper-ocean heat content and heat transport convergence in the western North Atlantic. J. Phys. Oceanogr., 37, 2682-2697, https://doi.org/10.1175/2007JPO3645.1.

Häkkinen, S., P. B. Rhines, and D. L. Worthen, 2015: Heat content variability in the North Atlantic Ocean in ocean reanalyses. Geophys. Res. Lett., 42, 2901-2909, https://doi.org/10.1002/ 2015 GL063299.

Jayne, S. R., and J. Marotzke, 2001: The dynamics of ocean heat transport variability. Rev. Geophys., 39, 385-411, https://doi.org/ 10.1029/2000RG000084.

Jolliffe, I. T., and D. B. Stephenson, 2012: Forecast Verification: A Practitioner's Guide in Atmospheric Science. Vol. 2. 2nd ed. Wiley and Sons, $292 \mathrm{pp}$.

Jungclaus, J. H., and Coauthors, 2013: Characteristics of the ocean simulations in the Max Planck Institute Ocean Model (MPIOM) the ocean component of the MPI-Earth system model. J. Adv. Model. Earth Syst., 5, 422-446, https://doi.org/ 10.1002/jame.20023.

Keenlyside, N. S., M. Latif, J. Jungclaus, L. Kornblueh, and E. Roeckner, 2008: Advancing decadal-scale climate prediction in the North Atlantic sector. Nature, 453, 84-88, https:// doi.org/10.1038/nature06921.

Klöwer, M., M. Latif, H. Ding, R. Greatbatch, and W. Park, 2014: Atlantic meridional overturning circulation and the prediction of North Atlantic sea surface temperature. Earth Planet. Sci. Lett., 406, 1-6, https://doi.org/ 10.1016/j.epsl.2014.09.001.

Lozier, M. S., and Coauthors, 2017: Overturning in the subpolar North Atlantic Program: A new international ocean observing system. Bull. Amer. Meteor. Soc., 98, 737-752, https://doi.org/ 10.1175/BAMS-D-16-0057.1.
Matei, D., H. Pohlmann, J. Jungclaus, W. Müller, H. Haak, and J. Marotzke, 2012: Two tales of initializing decadal climate prediction experiments with the ECHAM5/MPI-OM model. J. Climate, 25, 8502-8523, https://doi.org/10.1175/ JCLI-D-11-00633.1.

Müller, W. A., and Coauthors, 2012: Forecast skill of multi-year seasonal means in the decadal prediction system of the Max Planck Institute for Meteorology. Geophys. Res. Lett., 39, L22707, https://doi.org/10.1029/2012GL053326.

_ H. Pohlmann, F. Sienz, and D. Smith, 2014: Decadal climate predictions for the period 1901-2010 with a coupled climate model. Geophys. Res. Lett., 41, 2100-2107, https://doi.org/ 10.1002/2014GL059259.

_, and Coauthors, 2015: A twentieth-century reanalysis forced ocean model to reconstruct the North Atlantic climate variation during the 1920s. Climate Dyn., 44, 1935-1955, https:// doi.org/10.1007/s00382-014-2267-5.

Palmer, T. N., and Coauthors, 2004: Development of a European Multimodel Ensemble System for Seasonal-to-Interannual Prediction (DEMETER). Bull. Amer. Meteor. Soc., 85, 853872, https://doi.org/10.1175/BAMS-85-6-853.

Pohlmann, H., J. Kröger, R. J. Greatbatch, and W. A. Müller, 2017: Initialization shock in decadal hindcasts due to errors in wind stress over the tropical Pacific. Climate Dyn., 49, 2685-2693, https://doi.org/10.1007/s00382-016-3486-8.

Rayner, N., D. Parker, E. Horton, C. Folland, L. Alexander, D. Rowell, E. Kent, and A. Kaplan, 2003: Global analyses of sea surface temperature, sea ice, and night marine air temperature since the late nineteenth century. J. Geophys. Res., 108, 4407, https://doi.org/10.1029/2002JD002670.

Robson, J., R. Sutton, and D. Smith, 2012: Initialized decadal predictions of the rapid warming of the North Atlantic Ocean in the mid 1990s. Geophys. Res. Lett., 39, L19713, https://doi.org/ 10.1029/2012GL053370.

, — - and — 2013: Predictable climate impacts of the decadal changes in the ocean in the 1990s. J. Climate, 26, 63296339, https://doi.org/10.1175/JCLI-D-12-00827.1.

- ——, and — 2014: Decadal predictions of the cooling and freshening of the North Atlantic in the 1960s and the role of ocean circulation. Climate Dyn., 42, 2353-2365, https://doi.org/ 10.1007/s00382-014-2115-7.

—, I. Polo, D. L. Hodson, D. P. Stevens, and L. C. Shaffrey, 2018: Decadal prediction of the North Atlantic subpolar gyre in the HiGEM high-resolution climate model. Climate Dyn., 50, 921-937, https://doi.org/\%2010.1007/ s00382-017-3649-2.

Sanchez-Gomez, E., C. Cassou, Y. Ruprich-Robert, E. Fernandez, and L. Terray, 2016: Drift dynamics in a coupled model initialized for decadal forecasts. Climate Dyn., 46, 1819-1840, https://doi.org/10.1007/s00382-015-2678-y.

Sheen, K., D. Smith, N. Dunstone, R. Eade, D. Rowell, and M. Vellinga, 2017: Skilful prediction of Sahel summer rainfall on inter-annual and multi-year time scales. Nat. Commun., 8 , 14966, https://doi.org/10.1038/ncomms14966.

Smith, D. M., S. Cusack, A. W. Colman, C. K. Folland, G. R. Harris, and J. M. Murphy, 2007: Improved surface temperature prediction for the coming decade from a global climate model. Science, 317, 796-799, https://doi.org/10.1126/ science.1139540.

, R. Eade, and H. Pohlmann, 2013: A comparison of full-field and anomaly initialization for seasonal to decadal climate prediction. Climate Dyn., 41, 3325-3338, https://doi.org/ 10.1007/s00382-013-1683-2. 
Stevens, B., and Coauthors, 2013: Atmospheric component of the MPI-M Earth System Model: ECHAM6.J. Adv. Model. Earth Syst., 5, 146-172, https://doi.org/10.1002/jame.20015.

Visbeck, M., J. Hurrell, L. Polvani, and H. Cullen, 2001: The North Atlantic Oscillation: Past, present, and future. Proc. Natl. Acad. Sci. USA, 98, 12876-12877, https://doi.org/10.1073/ pnas.231391598.

Yeager, S., A. Karspeck, G. Danabasoglu, J. Tribbia, and H. Teng, 2012: A decadal prediction case study: Late twentieth-century North Atlantic Ocean heat content. J. Climate, 25, 5173-5189, https://doi.org/10.1175/JCLI-D-11-00595.1.

Zhang, J., and R. Zhang, 2015: On the evolution of Atlantic Meridional Overturning Circulation fingerprint and implications for decadal predictability in the North Atlantic. Geophys. Res. Lett., 42, 5419-5426, https://doi.org/10.1002/2015GL064596.
Zhang, R., 2008: Coherent surface-subsurface fingerprint of the Atlantic meridional overturning circulation. Geophys. Res. Lett., 35, L20705, https://doi.org/10.1029/2008GL035463.

_ 2010: Latitudinal dependence of Atlantic meridional overturning circulation (AMOC) variations. Geophys. Res. Lett., 37, L16703, https://doi.org/10.1029/2010GL044474.

— 2017: On the persistence and coherence of subpolar sea surface temperature and salinity anomalies associated with the Atlantic multidecadal variability. Geophys. Res. Lett., 44, 7865-7875, https://doi.org/10.1002/2017GL074342.

-, R. Sutton, G. Danabasoglu, T. L. Delworth, W. M. Kim, J. Robson, and S. G. Yeager, 2016: Comment on "The Atlantic Multidecadal Oscillation without a role for ocean circulation." Science, 352, 1527-1527, https://doi.org/10.1126/ science.aaf1660. 